Quim. Nova, Vol. 31, No. 1, 10-19, 2008

\title{
AVALIAÇÃo DA CONTAMINAÇÃO POR ELEMENTOS METÁLICOS DOS SEDIMENTOS DO ESTUÁRIO SANTOS - SÃO VICENTE
}

\author{
Marcos Antonio Hortellani* e Jorge E. S. Sarkis \\ Centro de Química e Meio Ambiente, Instituto de Pesquisas Energéticas e Nucleares, Av. Prof. Lineu Prestes, 2242, 05508-000 \\ São Paulo - SP, Brasil \\ Denis M. S. Abessa \\ Departamento de Biologia Marinha e Gerenciamento Costeiro, Campus do Litoral Paulista, Universidade Estadual Paulista, \\ Praça Infante Dom Henrique, s/n, 011330-900 São Vicente - SP, Brasil \\ Eduinetty C. P. M. Sousa \\ Departamento de Oceanografia Biológica, Instituto Oceanográfico, Universidade de São Paulo, Praça do Oceanográfico, 191, \\ 05508-900 São Paulo - SP, Brasil
}

Recebido em 4/7/06; aceito em 25/5/07; publicado na web em 3/12/07

\begin{abstract}
ASSESSMENT OF METALLIC ELEMENT CONTAMINATION IN SEDIMENTS FROM THE SANTOS - SÃO VICENTE ESTUARINE SYSTEM.Three approaches were applied to evaluate metal contamination in 41 sediment samples from the Santos São Vicente Estuarine System: normalization to Al, statistical analysis and sediment quality guidelines (SQGs). The results showed increases in the concentrations of $\mathrm{Zn}, \mathrm{Ni}, \mathrm{Pb}, \mathrm{Cd}, \mathrm{Cr}$ and $\mathrm{Hg}$, which seemed to be associated with human activities. The levels of $\mathrm{Al}, \mathrm{Fe}$ and Co probably were associated with crustal material or natural weathering processes. About $45 \%$ of the samples presented concentrations exceeding TEL-ERL, levels occasionally associated with adverse biological effects. Four of these samples presented concentrations above PEL-ERM, levels frequently associated with adverse biological effects.
\end{abstract}

Keywords: sediments; metal contamination; normalization.

\section{INTRODUÇÃO}

A poluição dos sedimentos está intimamente ligada com a poluição das águas e tem origem em diversas fontes, dentre as quais se destacam $^{1}$ : efluentes domésticos, efluentes industriais, carga difusa urbana e agrícola. A situação é mais crítica nas regiões em que existem atividades portuárias, depósito de resíduos industriais e urbanos.

Sedimentos têm sido amplamente utilizados como indicadores ambientais, porque possuem grande capacidade de incorporar e acumular elementos contaminantes. Como os sedimentos são levados pelos rios para outro curso de água ou para o mar, as análises dos sedimentos em vários pontos de uma região de interesse servem para rastrear fontes de contaminação ou monitorar esses contaminantes ${ }^{2}$.

A ocorrência de variações nas características físicas e químicas do meio (como pH, salinidade, conteúdo de quelantes orgânicos, entre outras) pode liberar um poluente incorporado ao sedimento. Portanto, mudanças nas condições ambientais e dragagens podem transformar os sedimentos em fontes de contaminação ${ }^{3}$. Além disso, já foi comprovado que para a comunidade bentônica, além da coluna d' água, há diferentes vias de exposição aos contaminantes, como pelo simples contato direto ${ }^{4}$ ou pela ingestão dos sedimentos ${ }^{5}$.

O Estuário de Santos - São Vicente (Figura 1) é uma região particularmente muito exposta à poluição, por ter um grande parque industrial, ser portuária, populosa e, ainda, ter atividades de agricultura e pecuária. As principais fontes de poluição estão relacionadas às atividades do parque industrial de Cubatão, assim como às disposições irregulares de resíduos sólidos industriais, às dragagens do canal do porto e das atividades portuárias, às estações de tratamento de esgotos, ao emissário submarino, além das descargas de esgotos domésticos clandestinos e aos aterros sanitários (lixão) e, até, às des-

*e-mail:mahortel@ipen.br cargas da represa Billings. As alterações físicas da região, naturais ou não, como as resultantes de erosão, assoreamento, aterros de canais e manguezais, intervenções no sistema de drenagem etc., também interferem no grau de contaminação da região ${ }^{6}$.

As diversas e numerosas indústrias existentes no local podem ser agrupadas de acordo com seus produtos e potenciais de emissão de metais poluentes em seus efluentes. Essas fontes potenciais que correspondem à detecção de determinado metal poluente pela CETESB $^{6}$ no período de avaliação (1984 a 2000), mesmo quando os níveis atendem aos padrões legais de lançamento ou os lançamentos são esporádicos ou eventuais, resultou na seguinte divisão: uma indústria siderúrgica com potencial de emissão dos elementos metálicos $\mathrm{Cu}, \mathrm{Mn}, \mathrm{Ni}$, e $\mathrm{Zn}$; 2 refinarias de petróleo com potenciais de emissão de $\mathrm{Cu}, \mathrm{Cr}, \mathrm{Ni}$, $\mathrm{Hg}$ e Zn; 11 indústrias químicas e petroquímicas com potenciais de emissão de $\mathrm{Cd}, \mathrm{Cu}, \mathrm{Cr}, \mathrm{Mn}, \mathrm{Ni}, \mathrm{Pb}, \mathrm{Zn}$ e $\mathrm{Hg}$ e, 7 indústrias de fertilizantes com potenciais de emissão de $\mathrm{Pb}$, Ni e $\mathrm{Zn}$. Entre essas últimas existem 4 indústrias de fertilizantes fosfatados que já produziram como resíduo cerca de 69 milhões de $\mathrm{t}$ de fosfogesso ${ }^{7}$, estocadas em imensas pilhas a céu aberto ao lado da rodovia Piaçagüera-Guarujá, com potencial de emissão de radionuclídeos ${ }^{7-9}$.

$\mathrm{Na}$ Baixada Santista também existem locais onde ocorre a disposição de sedimentos contaminados provenientes das dragagens dos rios do estuário (Figura 1). Por exemplo, o Canal do Porto deve ser dragado pelo menos uma vez por ano para que a profundidade necessária para passagem dos navios seja preservada. Após 1996 até o momento, todo o material dragado nesse canal foi disposto, sem tratamento, no mar próximo à Ilha da Moela ${ }^{6}$.

O Porto de Santos é o maior da América Latina. Possui uma extensão de cerca de $10 \mathrm{~km}$ a partir da baía de Santos, possui largura entre 200 e $300 \mathrm{~m}$ e profundidade mínima variando de 5 a $14 \mathrm{~m}$.

No Porto de Santos há vários terminais de embarque de produtos, dentre os quais se destacam os grãos de cereais (soja, milho, trigo), 


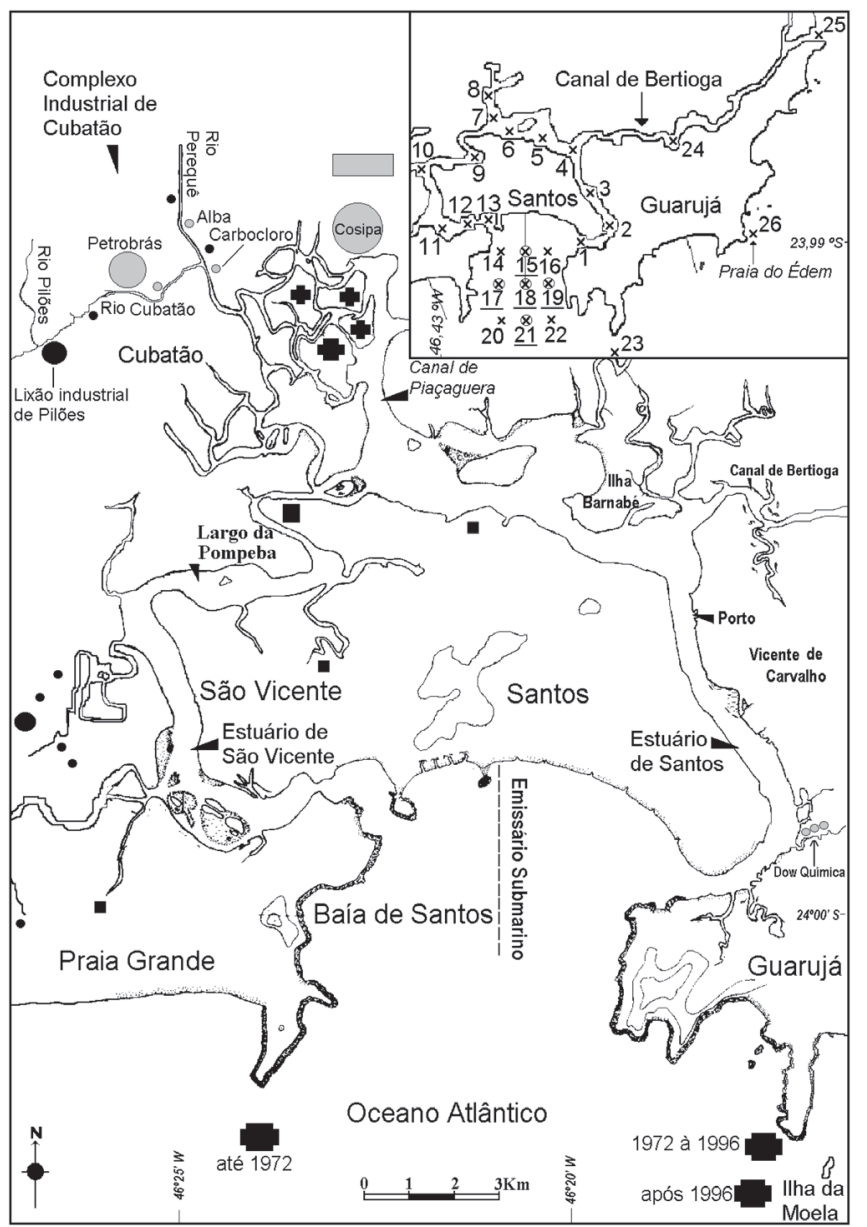

= áreas industriais com solo contaminado;

= depósitos de resíduos sólidos doméstico (lixão);

+ = Locais de disposição de sedimantos dragados contaminados;

- disposição de resíduos industriais;

= pilhas de fosfogesso proveniente das indústrias de fertilizantes fosfatados (impacto radioativo ${ }^{7-9}$ )

Figura 1. Localização das áreas contaminadas com resíduos sólidos na Baixada Santista (em 1999) (modificado de CETESB) ${ }^{6}$ e a localização dos pontos de coleta. Os cinco pontos entre círculos e sublinhados localizados na baia de Santos foram os pontos utilizados para a análise sazonal

açúcar, fertilizantes, outros granéis sólidos, granéis líquidos, inflamáveis na Ilha Barnabé e oxidantes. Há, também, terminais de uso privativo, como os da Cosipa, Ultrafértil, Dow Química e outros. Perdas durante as operações de carga/descarga, armazenamento, transferências de produtos químicos e as lavagens dos "isocontainers", constituem-se em fontes de materiais poluentes para as águas do sistema estuarino de Santos - São Vicente. Essas perdas ocorrem, também, além do porto, por toda a sua proximidade onde existem armazéns, silos, depósitos de combustíveis, terminais de petróleo, pátios de manobras etc. ${ }^{6,10}$. Além disso, há também a poluição provocada pelas tripulações dos navios, pelas suas manutenções com lavagem de porões e até pela lixiviação dos cascos e tintas.

Apesar das melhorias das condições ambientais alcançadas graças a um rigoroso controle das fontes poluidoras implantado pela CETESB a partir de 1984, que possibilitou o retorno para os rios, estuário e manguezais de alguns crustáceos, peixes e aves ${ }^{11}$, estudos recentes ${ }^{6,12-16}$ têm encontrado concentrações de metais nos sedimentos de superfície dessa região acima de valores limites estabelecidos por critérios de qualidade de sedimentos e adotados pela CETESB, abaixo dos quais não são observados efeitos adversos à comunidade biológica.

Este trabalho descreve uma avaliação da contaminação dos sedimentos aquáticos provenientes do estuário Santos - São Vicente e da baía de Santos por alguns elementos metálicos, com a indicação das áreas mais críticas em relação à contaminação. Essa avaliação foi elaborada após análises quimiométricas, normalização dos resultados com o teor de $\mathrm{Al}$ e comparação com critérios indicativos da qualidade dos sedimentos descritos na literatura.

\section{PARTE EXPERIMENTAL}

\section{Área de estudo}

Um total de 41 amostras de sedimentos foram coletadas com auxílio de um pegador de fundo do tipo "Petersen", de 0,026 $\mathrm{m}^{2}$ de embocadura $^{14}$, a partir da embarcação inflável "Luan" do IO-USP 4 , em locais e datas assim distribuídas: 26 amostras coletadas em março de 1998 (verão) no Estuário e Baía de Santos, 15 amostras próximas às saídas do difusor do emissário submarino de Santos/São Vicente, tendo sido coletadas 10 em 1999, 5 em março (verão) e 5 em setembro (inverno); as últimas 5 amostras foram coletadas em março de 2000 (verão). As localizações exatas dos pontos de coletas nas várias amostragens, para assegurar o mesmo local, foram determinadas por GPS (Sistema de Posicionamento Geográfico) e estão esquematizadas na Figura 1.

As amostras encaminhadas para as determinações dos teores dos metais foram retiradas da porção central do material retido no pegador (sem contato com as paredes do mesmo), acondicionadas em sacos plásticos e congeladas a $-15^{\circ} \mathrm{C}$ até o momento da secagem. Os sedimentos foram secos ao ar em capelas de fluxo laminar, para evitar perda de elementos voláteis.

\section{Preparação do material sedimentológico}

Em todas as amostras destinadas à determinação dos elementos desse trabalho, as frações de pedregulhos e das areias grossa e muito grossa foram separadas. Assim, utilizaram-se as porções dos sedimentos $(<0,50 \mathrm{~mm})$ que englobam as granulometrias correspondentes à de areia média, fina, muito fina, silte e argila. Em seguida, as amostras foram pulverizadas em almofariz de ágata até passarem por peneiras de 80 mesh.

\section{Metodologia}

Os elementos $\mathrm{Cd}, \mathrm{Co}, \mathrm{Hg}, \mathrm{Ni}, \mathrm{Pb}$ e $\mathrm{Zn}$ foram determinados utilizando um espectrômetro de absorção atômica marca Varian (modelo-Spectra AA-220-Fast Sequencial), após lixiviação dos sedimentos com uma mistura de ácidos grau p.a. e isentos em $\mathrm{Hg}$, sob refluxo ${ }^{15}$, para se evitar perdas de elementos voláteis, como Zn e $\mathrm{Hg}$. Pesou-se uma massa de $0,500 \mathrm{~g}$ de cada sedimento e adicionaram-se $4 \mathrm{~mL}$ de água régia, $1 \mathrm{~mL}$ de água e $1 \mathrm{~mL}$ de $\mathrm{HCLO}_{4}$, aquecendo-se por $30 \mathrm{~min}$ a $90{ }^{\circ} \mathrm{C}$ em chapa aquecedora, de acordo com uma modificação do procedimento de Akagi ${ }^{17}$. A solução resultante foi filtrada e transferida para balão volumétrico aferido de $25 \mathrm{~mL}$. $\mathrm{O}$ volume foi completado com água Milli-Q.

O mercúrio foi analisado utilizando-se um sistema de injeção em fluxo, FIA ${ }^{18}$, onde uma válvula de injeção manual injeta $500 \mu \mathrm{L}$ da amostra digerida em um fluxo de $10 \mathrm{~mL} \mathrm{~min}^{-1}$ de água Milli-Q, que se encontra $30 \mathrm{~cm}$ à frente, conectado por um tubo de PTFE (30 $\mathrm{cm}$ ), com um fluxo de $1 \mathrm{~mL} \mathrm{~min}^{-1}$ de $\mathrm{SnCl}_{2} 25 \%$ (m/v) em $\mathrm{HCl} 25 \%$ (v/v) que reduz o $\mathrm{Hg}^{2+}$ para $\mathrm{Hg}^{0}$. $\mathrm{O}$ mercúrio reduzido encontra-se 
$30 \mathrm{~cm}$ à frente, conectado por um tubo de PTFE $(30 \mathrm{~cm})$, com um fluxo de gás de arraste (argônio a $200 \mathrm{~mL} \mathrm{~min}^{-1}$ ), utilizado para separar o vapor de $\mathrm{Hg}^{0}$ no separador de fases gás-líquido localizado $10 \mathrm{~cm}$ à frente, conectado por um tubo de PTFE $(10 \mathrm{~cm})$ e finalmente conduzir o vapor de $\mathrm{Hg}^{0}$ por um tubo de PTFE de $30 \mathrm{~cm}$ até a célula de quartzo acoplada ao espectrômetro de absorção atômica. Todas as determinações foram feitas em duas replicatas.

Os outros elementos foram determinados por AAS pelo modo chama.

Para os elementos $\mathrm{Fe}, \mathrm{Al}$ e $\mathrm{Cr}$ foram conseguidos baixos níveis de recuperação pela lixiviação. Como o nosso objetivo era conseguir extração total para todos os elementos estudados e, porque para se utilizar o $\mathrm{Al}$ como elemento normalizador seria necessário nível de recuperação próximo a $100 \%$, foram utilizadas dissoluções completas em forno de microondas da marca CEM, modelo MARS 5, de acordo com as recomendações de $\mathrm{Krause}^{19}$. O procedimento consistiu na pesagem $100 \mathrm{mg}$ de cada amostra e/ou material de referência certificado, sua transferência para frascos de teflon HP-500, seguido da adição de água Milli-Q e uma série de ácidos concentrados, todos de grau p.a. da marca Merck, agitando-se após cada adição, na seguinte sequiência: $10 \mathrm{~mL}$ de $\mathrm{H}_{2} \mathrm{O}, 5$ $\mathrm{mL}$ de $\mathrm{HNO}_{3}, 4 \mathrm{~mL}$ de $\mathrm{HF}$ e $1 \mathrm{~mL}$ de $\mathrm{HCL}^{14}$.

O programa de digestão utilizado foi o descrito a seguir: $\mathrm{n}^{\circ}$ de estágios: 1; tempo: $20 \mathrm{~min}$; potência: $1200 \mathrm{~W}$; tempo de rampa: 10 min; pressão: 175 Psi; temperatura máxima: $210{ }^{\circ} \mathrm{C}$.

Após a digestão das amostras e/ou materiais de referência, as soluções resultantes foram avolumadas até $50 \mathrm{~mL}$ com água Milli-Q. Para a determinação dos elementos $\mathrm{Fe}$ e $\mathrm{Al}$, foram necessárias diluições adicionais de 20 vezes. A determinação de $\mathrm{Cr}$ foi feita sem diluição. Para essas análises foi utilizada pérola de teflon no nebulizador do AAS para evitar o ataque de HF eventualmente remanescente.

\section{Análises quimiométricas}

Com o objetivo de se estudar possíveis relações entre os teores dos metais encontrados nos sedimentos, foram calculadas as correlações de Pearson, de acordo com Zar ${ }^{20}$, a um nível de significância $\mathrm{p}=0,01$, verificando a existência de uma possível relação linear entre dois dos valores quantitativos através do coeficiente $r$.

Para se identificar grupos de elementos com comportamento similar e o comportamento geral dos dados, foram utilizadas duas técnicas quimiométricas de classificação, a análise de componentes principais (PCA) e a análise de agrupamentos ou Clusters hierárquicos (HCA), usando o programa computacional SPSS ("Statistical Package for the Social Sciences", versão 10.0) ${ }^{21}$.

A PCA consiste numa manipulação da matriz de dados com o objetivo de simplificar as variações presentes em muitas variáveis, representando-as em um número menor de fatores, componentes principais, contendo informações para representar as amostras ou ainda auto vetores contendo informações sobre como cada variável se relaciona com as demais variáveis. Assim, a natureza multivariada dos dados pode ser representada em poucas dimensões ${ }^{22}$.

A HCA foi utilizada para classificar as variáveis (elementos químicos) e as amostras de sedimentos de acordo com a similaridade da composição química (concentração dos elementos metálicos).

$\mathrm{Na}$ HCA, inicialmente cada amostra é tratada individualmente e, então, a matriz similaridade é analisada; em cada passo se diminui uma dimensão da matriz, isto é, as amostras são gradativamente fundidas em grupos. O processo é repetido até que todas as amostras se reúnam em um único grupo de acordo com o grau de similaridade ${ }^{23}$. $\mathrm{O}$ resultado dessa análise é expresso na forma de dendogramas, que são gráficos bidimensionais de fácil visualização. Para a formação desses grupos foram testados vários métodos de agrupamentos disponíveis no programa estatístico SPSS ${ }^{21}$. O método Ward (método da variância mínima) foi o método utilizado neste trabalho, por ter apresentado os melhores resultados. O método Ward incorpora um objeto a um grupo se essa união proporcionar a menor variância no sistema ${ }^{24}$.

\section{Normalização dos dados}

Normalização é um procedimento comum utilizado para detectar e quantificar concentrações irregulares de metais em sedimentos.

Os procedimentos de normalização podem ser agrupados em cinco categorias principais ${ }^{25}$ : normalização mecânica pelo tamanho; extrapolação da curva de regressão; correção com mineral inerte; determinação química somente da fração móvel e, comparação com elemento conservativo - Fator de Enriquecimento (EF).

A concentração natural de metais em sedimentos é determinada não somente pelo tamanho dos grãos, mas também, fundamentalmente, pela composição dos minerais e compostos secundários ${ }^{26}$.

Resultados obtidos por Hortellani et al. ${ }^{15}$ demonstraram que a contaminação por $\mathrm{Hg}$ dessa região estuarina pode ser avaliada pela normalização com o teor de Lama (silte + argila), utilizando dois procedimentos de normalização (extrapolação da curva de regressão e Fator de Enriquecimento).

Neste trabalho também foram utilizadas essas duas técnicas de normalização com o intuito de se eliminar as desvantagens de cada uma (extrapolação da curva de regressão e Fator de Enriquecimento). O teor de alumínio foi usado para normalizar a concentração dos elementos metálicos nos sedimentos dessa região, devido ao fato de alumino-silicatos serem os principais constituintes da fração fina (Lama) dos sedimentos com a qual os traços de metais estão associados ${ }^{27}$.

\section{RESULTADOS E DISCUSSÃO}

Os níveis de recuperação das digestões ácidas e das determinações dos metais por AAS foram testados utilizando-se um material de referência certificado (no 2704 - "Bufalo River Sediment"), analisado em 3 replicatas. A recuperação para a maioria dos metais foi $>90 \%$ (Tabela 1), exceto para o $\mathrm{Cr}(60,4 \%)$. Isso pode ser explicado pelo fato de que esse material certificado não apresentou uma solubilização total na digestão por microondas, ao contrário das amostras que tiveram uma excelente solubilização, além de que o $\mathrm{Cr}$, sendo um elemento refratário, está fortemente ligado a silicatos de difícil solubilização. Outros trabalhos ${ }^{28,29}$ também encontraram baixa recuperação para o elemento $\mathrm{Cr}$.

Devido à baixa recuperação do crômio no sedimento de referência, procedeu-se à abertura de outro material de referência certificado (Material no $1646^{\mathrm{a}}$ - "Estuarine Sediment “- do "NIST Standard Reference Materials"), com a mesma digestão ácida. Esse material certificado apresentou uma boa solubilização, com uma recuperação para o $\mathrm{Cr}>90 \%$ (Tabela 1). Para a avaliação da exatidão do procedimento foi calculado o $\mathrm{Z}$ score que, de acordo com o INMETRO $^{30}$, é uma das maneiras para se avaliar o desempenho do laboratório utilizando material de referência certificado. Para todos os elementos analisados o Z score obtido (|Z|) foi menor ou igual a 2, indicando que os métodos analíticos utilizados são satisfatórios.

Os limites de detecção $(L D)$ e de determinação $(L Q)$ foram avaliados analisando-se as provas em branco da preparação, baseado nas orientações sobre Validação de Métodos de Ensaios Químicos do INMETRO ${ }^{30}$. O $L D$ foi obtido de acordo com a seguinte equação $(L D=\bar{X}+3 s)$, onde $(\bar{X})$ representa a média das determinações de 7 preparações distintas de provas em branco mais 3 vezes a estimativa do desvio padrão $(s)$ obtido na determinação dessas 7 preparações das provas em branco. O limite de determinação $(L Q)$ foi obtido de acordo com a seguinte equação $(L D=\bar{X}+5 s)$, enquanto que os limites finais de determinação $\left(L Q_{f}\right)$ foram obtidos considerando 
Tabela 1. Figuras de mérito analítico dos procedimentos empregados, utilizando o material de referência:"Bufalo River Sediment"

\begin{tabular}{|c|c|c|c|c|c|c|c|}
\hline \multirow[t]{2}{*}{ Elementos } & \multicolumn{2}{|c|}{ Valores $\left(\mu \mathrm{g} \mathrm{g}^{-1}\right)$} & \multirow{2}{*}{$\begin{array}{c}\text { Recuperação } \\
\%\end{array}$} & \multirow{2}{*}{$\begin{array}{l}|\mathrm{Z}| \\
\text { score }\end{array}$} & \multirow{2}{*}{$\begin{array}{c}L D \\
\mu \mathrm{g} \mathrm{mL} L^{-1}\end{array}$} & \multirow{2}{*}{$\begin{array}{c}L Q \\
\mu \mathrm{g} \mathrm{mL} L^{-1}\end{array}$} & \multirow{2}{*}{$\begin{array}{c}L Q_{f} \\
\mu \mathrm{g} \mathrm{g}^{-1}\end{array}$} \\
\hline & Encontrado $^{\mathrm{a}}$ & Certificado & & & & & \\
\hline $\mathrm{Zn}$ & $430,8 \pm 9,2$ & $438 \pm 12$ & 98,4 & 0,6 & 0,06 & 0,10 & 5,0 \\
\hline $\mathrm{Ni}$ & $43,9 \pm 2,0$ & $44,1 \pm 3,0$ & 99,6 & 0,1 & 0,01 & 0,02 & 2,0 \\
\hline $\mathrm{Co}$ & $14,5 \pm 0,7$ & $14,0 \pm 0,6$ & 103,6 & 0,8 & 0,002 & 0,004 & 0,2 \\
\hline $\mathrm{Cd}$ & $3,50 \pm 0,13$ & $3,45 \pm 0,22$ & 101,4 & 0,2 & 0,005 & 0,01 & 0,5 \\
\hline $\mathrm{Pb}$ & $153,0 \pm 10,2$ & $161 \pm 17$ & 95,0 & 0,5 & 0,02 & 0,04 & 2,0 \\
\hline${ }^{\mathrm{b}} \mathrm{Cr}$ & $36,8 \pm 2,3$ & $40,9 \pm 1,9$ & 90,0 & 1,8 & 0,01 & 0,02 & 5,0 \\
\hline $\mathrm{Hg}$ & $1,48 \pm 0,06$ & $1,47 \pm 0,07$ & 100,68 & 0,1 & ${ }^{c} 0,47$ & ${ }^{\mathrm{c}} 0,65$ & 0,03 \\
\hline $\mathrm{Al}$ & $* 6,17 \pm 0,10$ & $* 6,11 \pm 0,16$ & 101,0 & 0,4 & 1,00 & 1,34 & $* 0,07$ \\
\hline $\mathrm{Fe}$ & $* 4,31 \pm 0,14$ & $* 4,11 \pm 0,10$ & 104,9 & 2,0 & 0,01 & 0,02 & $* 0,001$ \\
\hline
\end{tabular}

${ }^{\mathrm{a}}$ Média e estimativa do desvio padrão de três replicatas. ${ }^{\mathrm{b}}$ As figuras de mérito analítico para determinação de Cr foram obtidas utilizando-se um outro material de referência certificado $\mathrm{n}^{\circ} 1646^{\mathrm{a}}$ - "Estuarine Sediment". ' $\mathrm{O}$ valores de $L D$ e $L Q$ para o $\mathrm{Hg}$ estão em $\mu \mathrm{g} \mathrm{L}^{-1}$. * Valores em \%

a massa das amostras e as diluições utilizadas.

Para a verificação do impacto causado pela presença desses metais poluentes, foram considerados dois critérios interpretativos para avaliar a qualidade dos sedimentos com relação aos poluentes químicos. Um desses critérios foi estabelecido pela legislação canadense $^{31}$ e adotado pela $\operatorname{CETESB}^{6}$, o qual definiu dois limites e três faixas para sedimentos de águas salobras e salinas: o TEL ("Threshold Effect Level"), que indica o nível abaixo do qual não ocorre efeito adverso à comunidade biológica; e o PEL ("Probable Effect Level”), que é o nível acima do qual é provável a ocorrência de efeito adverso à comunidade biológica e a faixa entre o TEL e o PEL representa uma possível ocorrência de efeito adverso à comunidade biológica. O outro é o critério americano estabelecido por Long et al. ${ }^{32}$ em 1995 que utilizou dados químicos e biológicos e realizou estudos de campo em sedimentos marinhos e estuarinos, definindo dois limites e três faixas para definir a qualidade dos sedimentos: o ERL ("effects range - low"), que indica o limite de concentração abaixo do qual os sedimentos raramente são tóxicos; o ERM ("effects range - medium"), indicando que os sedimentos provavelmente são tóxicos, quando algum elemento metálico ultrapassa esse valor $^{33}$ e a faixa maior que o ERL e menor que o ERM indica que os sedimentos possivelmente são tóxicos. Esses limites foram obtidos a partir de resultados de extração total e os traços de metais foram excluídos quando não foi utilizada digestão com ácidos fortes ${ }^{32}$. Os limites ERL e ERM foram adotados pelo CONAMA na resolução CONAMA 344/04 para definir os níveis (3 e 4) de classificação dos sedimentos de águas salinas e salobras a serem dragados $^{34}$. No Art. $5 \mathrm{~V}$ dessa resolução está explícito que a extração deve ser feita com ácido forte em forno de microondas.

Na Tabela 2, encontram-se os níveis TEL - PEL ${ }^{31} e$ ERL $\mathbf{E R M}^{32}$ para alguns elementos avaliados neste trabalho. Nota-se que somente para o $\mathrm{Hg}$ os limites dos dois critérios são bem próximos, enquanto que para os outros elementos o critério americano sempre apresenta limites maiores que o canadense.

Os resultados obtidos pela média de duas replicatas para os elementos metálicos nas 41 amostras de sedimentos, utilizando os procedimentos descritos acima, estão relacionados na Tabela 3.

\section{Análise sazonal}

Foram feitas determinações dos níveis de elementos metálicos poluentes nos sedimentos coletados em cinco pontos localizados próximo às descargas do difusor do emissário submarino na baía de Santos, coletadas no verão de março de 1998, no verão de março de 1999, no inverno de setembro de 1999 e no verão de março de 2000 .
Tabela 2. Limites TEL ("Threshold Effect Level") - PEL ("Probable Effect Level") ${ }^{31}$ e ERL ("Effects Range - Low") -ERM ("Effects Range-Medium") ${ }^{32}$ para alguns elementos analisados

\begin{tabular}{lcccc}
\hline Elemento & $\begin{array}{c}\mathrm{TEL}^{\mathrm{a}} \\
\left(\mu \mathrm{g} \mathrm{g}^{-1}\right)\end{array}$ & $\begin{array}{c}\mathrm{PEL}^{\mathrm{a}} \\
\left(\mu \mathrm{g} \mathrm{g}^{-1}\right)\end{array}$ & $\begin{array}{c}\mathrm{ERL}^{b} \\
\left(\mu \mathrm{g} \mathrm{g}^{-1}\right)\end{array}$ & $\begin{array}{c}\mathrm{ERM}^{b} \\
\left(\mu \mathrm{g} \mathrm{g}^{-1}\right)\end{array}$ \\
\hline $\mathrm{Cd}$ & 0,7 & 4,21 & 1,2 & 9,6 \\
$\mathrm{Cr}$ & 52,3 & 160 & 81,0 & 370,0 \\
$\mathrm{Hg}$ & 0,13 & 0,70 & 0,15 & 0,71 \\
$\mathrm{Ni}$ & 15,9 & 42,8 & 20,9 & 51,6 \\
$\mathrm{~Pb}$ & 30,2 & 112 & 46,7 & 218,0 \\
$\mathrm{Zn}$ & 124 & 271 & 150,0 & 410,0 \\
\hline
\end{tabular}

${ }^{a}$ Sedimentos de água salobra e salinas: A classificação da água quanto à salinidade é a seguinte: Salobra: quando a salinidade está entre 0,50 e $30 \%$; Salina: quando a salinidade é $\geq 30,0 \%$; ${ }^{\text {b }}$ sedimentos estuarinos e marinhos.

Os efluentes de esgotos sanitários de Santos são tratados em estação de pré-condicionamento (EPC) onde passam por um gradeamento, peneiramento para remoção dos sólidos e por cloração. A seguir são encaminhados através de tubulações para serem lançados, pelos difusores do emissário submarino, no mar em uma área de alta circulação hidrodinâmica, na qual o efeito de diluição promove a melhoria das condições ambientais da região. Entretanto, estudos realizados por Abessa et al. ${ }^{14}$ concluíram que o emissário submarino é uma fonte de alterações para os sedimentos da área central da baía de Santos, causando mudanças nas características granulométricas, químicas e ecotoxicológicas.

Analisando-se os resultados para cada período, obtidos pelo valor da média e da estimativa do desvio padrão dos 5 pontos localizados próximos aos lançamentos dos difusores do emissário, foi observado que ocorreu apenas para o $\mathrm{Hg}$ certo aumento nos níveis com o decorrer do tempo. Esse aumento na média das concentrações de $\mathrm{Hg}$ foi cerca de $30 \%$ no período de 6 meses entre o final do inverno em setembro de $1999\left(0,10 \pm 0,03 \mu \mathrm{g} \mathrm{g}^{-1}\right)$ até o final do verão em março de $2000\left(0,13 \pm 0,05 \mu \mathrm{g} \mathrm{g}^{-1}\right)$. Maior que um aumento de $11 \%$ na média das concentrações de $\mathrm{Hg}$ observado no período de 6 meses que compreende o final do verão em março de 1999 $\left(0,09 \pm 0,06 \mu \mathrm{g} \mathrm{g}^{-1}\right)$ até o final do inverno em setembro de 1999 $\left(0,10 \pm 0,05 \mu \mathrm{g} \mathrm{g}^{-1}\right)$. Isso pode ter ocorrido devido à contribuição antrópica associada ao aumento dos lançamentos de efluentes de esgotos sanitários pelo emissário submarino que ocorre com o aumento da população flutuante nas cidades de Santos - São Vicente no verão. Observou-se, também, que a concentração média de $\mathrm{Hg}$ no período de 12 meses entre março de $1998\left(0,07 \pm 0,06 \mu \mathrm{g} \mathrm{g}^{-1}\right) \mathrm{e}$ 
Tabela 3. Teor de metais nos sedimentos coletados entre 1998/2000 e a profundidade (Prof.) da água no ponto de coleta

\begin{tabular}{|c|c|c|c|c|c|c|c|c|c|c|}
\hline Númerodo ponto & $\begin{array}{c}\mathrm{Al} \\
(\%)\end{array}$ & $\begin{array}{l}\mathrm{Fe} \\
(\%)\end{array}$ & 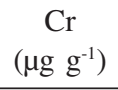 & $\begin{array}{c}\mathrm{Zn} \\
\left(\mu \mathrm{g} \mathrm{g}^{-1}\right)\end{array}$ & 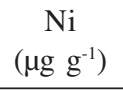 & 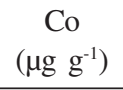 & 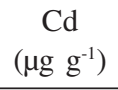 & $\begin{array}{c}\mathrm{Pb} \\
\left(\mu \mathrm{g} \mathrm{g}^{-1}\right)\end{array}$ & 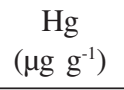 & $\begin{array}{c}\text { Prof. } \\
\text { (m) }\end{array}$ \\
\hline 1 & 3,04 & 1,21 & 18,7 & 40,1 & 9,5 & 6,0 & $<0,50$ & 10,9 & 0,11 & 10 \\
\hline 2 & 3,00 & 0,87 & 17,6 & 47,6 & 8,9 & 5,2 & $<0,50$ & 11,2 & 0,12 & 10 \\
\hline 3 & 3,11 & 0,92 & 7,5 & 44,5 & 7,0 & 4,2 & $<0,50$ & 10,8 & 0,36 & 9 \\
\hline 4 & 5,34 & 2,77 & 37,9 & 180,0 & 21,8 & 10,7 & 0,75 & 204,8 & 0,74 & 6 \\
\hline 5 & 5,21 & 2,68 & 44,1 & 284,4 & 22,2 & 10,3 & 0,92 & 23,5 & 0,23 & 4 \\
\hline 6 & 6,07 & 2,75 & 44,8 & 86,9 & 25,0 & 12,3 & 0,99 & 19,2 & 0,32 & 8 \\
\hline 7 & 7,91 & 4,99 & 65,8 & 152,8 & 34,1 & 17,0 & 0,42 & 39,7 & 0,92 & 9 \\
\hline 8 & 6,19 & 7,99 & 97,5 & 312,0 & 44,2 & 15,3 & 0,98 & 89,9 & 0,75 & 6 \\
\hline 9 & 3,33 & 1,76 & 22,8 & 77,6 & 13,2 & 5,1 & 1,49 & 19,6 & 0,50 & 5 \\
\hline 10 & 0,58 & 0,63 & $<5,0$ & 14,2 & 2,5 & 0,9 & $<0,50$ & 3,7 & 0,11 & 4 \\
\hline 11 & 5,91 & 2,85 & 53,6 & 37,9 & 10,2 & 4,8 & $<0,50$ & 10,3 & 0,31 & 6 \\
\hline 12 & 0,08 & 0,52 & $<5,0$ & 7,6 & 1,3 & 0,2 & $<0,50$ & 2,5 & 0,04 & 2 \\
\hline 13 & 0,06 & 0,62 & $<5,0$ & 10,9 & 2,4 & 1,1 & $<0,50$ & 17,0 & $<0,03$ & 2 \\
\hline 14 & 3,42 & 1,27 & 12,5 & 34,0 & 9,1 & 4,1 & $<0,50$ & 6,5 & 0,05 & 6 \\
\hline $15(4)^{*}$ & 2,71 & 1,77 & 18,8 & 41,4 & 11,3 & 5,8 & $<0,50$ & 8,3 & 0,04 & 7 \\
\hline 16 & 1,64 & 0,83 & 10,0 & 23,8 & 4,9 & 2,3 & $<0,50$ & 5,3 & 0,04 & 6 \\
\hline $17(2)^{*}$ & 2,96 & 1,25 & 18,4 & 35,9 & 10,3 & 5,4 & $<0,50$ & 7,8 & 0,04 & 11 \\
\hline $18(1)^{*}$ & 3,56 & 1,60 & 28,4 & 61,7 & 12,5 & 7,1 & $<0,50$ & 16,8 & 0,19 & 11 \\
\hline $19(5)^{*}$ & 3,75 & 1,70 & 29,0 & 44,7 & 13,4 & 6,5 & $<0,50$ & 11,8 & 0,06 & 10 \\
\hline 20 & 2,70 & 1,11 & 9,5 & 49,6 & 7,9 & 3,2 & $<0,50$ & 5,3 & 0,04 & 10 \\
\hline $21(3)^{*}$ & 2,60 & 1,23 & 19,6 & 32,2 & 14,7 & 4,1 & $<0,50$ & 5,8 & 0,04 & 12 \\
\hline 22 & 4,53 & 2,07 & 40,9 & 55,5 & 17,9 & 8,5 & $<0,50$ & 18 & 0,08 & 13 \\
\hline 23 & 2,28 & 1,14 & $<5,0$ & 29,7 & 8,1 & 3,8 & $<0,50$ & 5,5 & $<0,03$ & 18 \\
\hline 24 & 5,53 & 2,35 & 69,5 & 74,4 & 21,2 & 11,6 & 0,85 & 24,5 & 0,11 & 3 \\
\hline 25 & 1,00 & 0,61 & $<5,0$ & 16,8 & 5,9 & 1,6 & $<0,50$ & $<2,0$ & 0,04 & 2 \\
\hline 26 & 0,92 & 0,26 & $<5,0$ & 6,0 & 5,2 & 2,9 & $<0,50$ & 2,0 & $<0,03$ & 0,5 \\
\hline 27-Verão-99-(1)* & 4,15 & 2,46 & 34,8 & 57,2 & 17,4 & 8,55 & $<0,50$ & 17,4 & 0,09 & 11 \\
\hline 28-Verão-99- (2)* & 4,43 & 1,96 & 34,5 & 52,8 & 14,4 & 7,21 & $<0,50$ & 13,7 & 0,09 & 11 \\
\hline 29-Verão-99-(3)* & 3,87 & 1,89 & 23,5 & 42,6 & 13,4 & 6,92 & $<0,50$ & 10,2 & 0,05 & 12 \\
\hline 30-Verão-99-(4)* & 4,33 & 2,14 & 28,3 & 50,7 & 15,2 & 7,10 & $<0,50$ & 15,4 & 0,05 & 7 \\
\hline 31-Verão-99-(5)* & 4,35 & 2,31 & 23,9 & 51,4 & 14,3 & 7,39 & $<0,50$ & 14,9 & 0,17 & 10 \\
\hline 32-Inverno-99-(1)* & 6,06 & 2,47 & 74,9 & 83,3 & 26,5 & 13,5 & 0,85 & 28,0 & 0,13 & 11 \\
\hline 33-Inverno-99-(2)* & 4,90 & 1,96 & 111,7 & 53,1 & 14,6 & 7,2 & $<0,50$ & 14,0 & 0,12 & 11 \\
\hline 34-Inverno-99-(3)* & 4,15 & 1,91 & 37,2 & 57,6 & 16,7 & 6,8 & $<0,50$ & 17,0 & 0,08 & 12 \\
\hline 35-Inverno-99-(4)* & 4,55 & 2,14 & 31,4 & 51,3 & 15,1 & 7,3 & $<0,50$ & 15,5 & 0,07 & 7 \\
\hline 36-Inverno-99-(5)* & 4,67 & 2,31 & 21,4 & 52,3 & 16,1 & 7,4 & $<0,50$ & 14,5 & 0,10 & 10 \\
\hline 37-Verão-00-(1)* & 3,99 & 1,78 & 14,3 & 50,6 & 12,5 & 5,8 & $<0,50$ & 12,3 & 0,11 & 11 \\
\hline 38 -Verão-00-(2)* & 3,94 & 1,78 & 5,5 & 42,8 & 11,4 & 5,2 & $<0,50$ & 11,3 & 0,08 & 11 \\
\hline 39-Verão-00-(3)* & 4,31 & 2,02 & 18,0 & 44,6 & 12,4 & 5,4 & $<0,50$ & 8,9 & 0,10 & 12 \\
\hline 40-Verão-00-(4)* & 4,19 & 2,18 & 17,0 & 51,5 & 14,4 & 5,6 & $<0,50$ & 16,3 & 0,18 & 7 \\
\hline 41-Verão-00-(5)* & 5,25 & 3,25 & 38,0 & 65,6 & 20,9 & 11,2 & 0,65 & 26,0 & 0,18 & 10 \\
\hline
\end{tabular}

Valores acima do TEL e/ou ERL estão sublinhados e aqueles acima do PEL e/ou ERM estão identificados pela formatação da fonte em negrito. ( $)^{*}=n^{\circ}$ do ponto verão 1998 , correspondente às coletas subsequientes (análise sazonal)

março de $1999\left(0,09 \pm 0,05 \mu \mathrm{g} \mathrm{g}^{-1}\right)$ o aumento foi de $29 \%$ enquanto que no período de 12 meses entre março de $1999\left(0,09 \pm 0,05 \mu \mathrm{g} \mathrm{g}^{-1}\right)$ e março de $2000\left(0,13 \pm 0,05 \mu \mathrm{g} \mathrm{g}^{-1}\right)$ o aumento foi de $41 \%$. Baseado em estudos de variabilidade sazonal, essa situação pode ser atribuída ou à presença de fonte pontual de $\mathrm{Hg}$ nos efluentes do emissário submarino semelhante ao encontrado por Marins et al..$^{35}$, que estudou uma área costeira da região metropolitana de Fortaleza sob influência dos efluentes de um emissário submarino, ou ainda devido ao fato de que a maior quantidade de efluentes liberados no verão influenciou outros fatores que regulam a fixação ou a mobilização de $\mathrm{Hg}$ nos sedimentos, como as condições redox e de acidez do meio, que determinam a estabilidade dos compostos envolvidos na fixação do $\mathrm{Hg}^{16,36}$. Esses fatores ainda são influenciados por variações sazonais na temperatura e na pluviosidade ${ }^{16,37}$. Com base nesses resultados fica evidente a importância de análises sazonais, mostrando ser recomendável o monitoramento contínuo dessa área, visando garantir que os níveis de contaminação não ultrapassem limites seguros para a biota.

\section{Análises quimiométricas}

\section{Correlação entre os teores dos metais}

Os valores obtidos de $r$ (correlações de Pearson), que apresentam as principais correlações entre duas variáveis dos sedimentos aquáticos do estuário (41 amostras). Observou-se que os teores de $\mathrm{Al}, \mathrm{Fe}$ e Co apresentaram uma significante correlação com os outros metais, condição essa, de acordo com Aloupi et. al. ${ }^{26}$, necessária para que um elemento seja usado como elemento normalizador 
para os elementos anômalos, sugerindo que esses elementos fazem parte da constituição natural dos sedimentos ou resultados de processos climáticos naturais.

O alumínio e o ferro têm sido amplamente usados como elementos normalizadores ${ }^{26}$. O Al foi escolhido, por ser comprovado que os principais constituintes da fração fina dos sedimentos são alumino-silicatos associados aos traços de outros metais ${ }^{27}$ e ainda pelo fato do Fe não ter apresentado correlação com o $\mathrm{Cd}$.

Analisando-se o conjunto de dados da correlação entre duas variáveis, notam-se similaridades no comportamento de pares de variáveis, mas não se identificam grupos de elementos com comportamento similar. Por isso foram utilizadas a análise de componentes principais (PCA) e a análise de clusters hierárquicos (HCA), que são apropriadas para estudar as inter-relações entre as variáveis e também o comportamento geral dos dados.

Para a PCA e a HCA, foram utilizados os valores do limite de determinação $\left(\mathrm{LQ}_{\mathrm{f}}\right)$ e não zero para os elementos com os valores abaixo do $\mathrm{LQ}_{\mathrm{f}}$, pois, em ambos os casos são utilizados recursos matemáticos envolvendo operações com matrizes, nas quais apenas um elemento com valor igual zero anularia uma linha da matriz e, portanto, eliminaria uma amostra.

\section{Análise dos componentes principais}

Foi utilizada a PCA usando correlação de matriz para as 41 amostra de sedimentos aquáticos do estuário. Fazendo-se a análise das variâncias pelos parâmetros químicos, cada componente principal, gerado sem rotação varimax, apresentou uma variância distinta e cumulativa de componente para componente.

A técnica de rotação varimax ${ }^{38}$ faz a rotação ortogonal dos componentes para encontrar uma posição mais facilmente interpretável.

A variabilidade original das 41 amostras de sedimento foi sintetizada em 9 componentes principais. Desses componentes, o primeiro sintetizou $67,12 \%$ das informações originais e apresentou autovalor $=6,04$, o segundo $11,54 \%$ com autovalor $=1,03$ e o terceiro $8,18 \%$ com autovalor $=0,74$.

Os três primeiros componentes somados explicaram 86,83\% da variabilidade dos dados. Somente eles podem ser usados para uma análise, pois apresentam uma percentagem de variância acima ou próxima de $10 \%$ ou ainda autovalores acima ou próximos de 1 . Do quarto componente em diante, podemos desprezá-los por apresentarem percentagem de variância e/ou autovalores muito pequenos para que possam explicar alguma variabilidade dos sedimentos, sendo considerados por isso como resíduos de variância.

O primeiro componente concentrou informações a respeito dos teores de todos os elementos analisados. A seguir apresenta-se a correlação de cada elemento com o componente principal-1: $\mathrm{Al}(0,855), \mathrm{Fe}(0,919), \mathrm{Cr}(0,793), \mathrm{Ni}(0,960), \mathrm{Co}(0,926), \mathrm{Zn}(0,862)$, $\mathrm{Hg}(0,797), \mathrm{Pb}(0,638)$, e $\mathrm{Cd}(0,524)$. Esses valores explicam o porquê desse componente principal sintetizar cerca de $67,12 \%$ das informações sobre variabilidade das amostras.

O segundo componente principal apresentou uma maior correlação e, portanto, uma maior concentração de informações a respeito apenas dos elementos $\mathrm{Pb}(0,531)$ e $\mathrm{Cd}(0,463)$. O terceiro componente, o menos explicativo dos componentes significativos $(8,18 \%)$, mas que, ainda assim, explica alguma característica dos sedimentos, apresentou uma maior correlação e, portanto, concentrou informações a respeito do elemento $\mathrm{Cd}(0,701)$ e ainda uma correlação negativa significativa para o $\mathrm{Pb}(-0,425)$.

Posicionando-se as variáveis em um espaço tridimensional, como mostra a Figura 2a, pode-se observar que os elementos $\mathrm{Cd}, \mathrm{Pb}, \mathrm{Zn}$ e $\mathrm{Hg}$ foram separados pelo $\mathrm{CP} 2$ de um outro grupo formado pelo restante dos elementos que apresentam um comportamento similar. Verificamos também que o Cd foi separado pelo CP3 do grupo for- mado pelos elementos cuja aproximação sugere um comportamento semelhante, $\mathrm{Pb}, \mathrm{Zn}$ e $\mathrm{Hg}$.
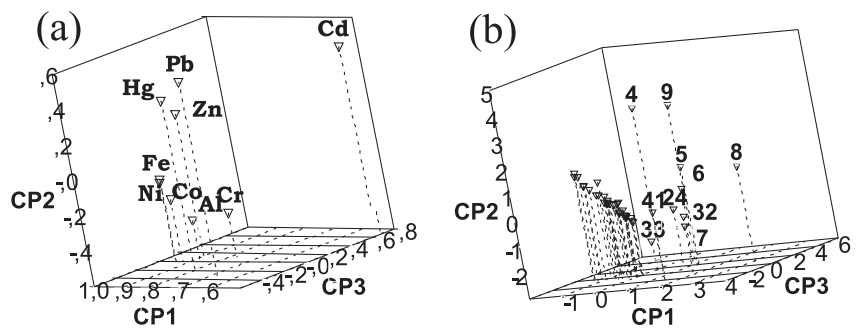

Figura 2. (a) Peso das variáveis nos três primeiros componentes principais da série de sedimentos, (b) distribuição tridimensional das 41 amostras de sedimentos em função das coordenadas dos 3 componentes principais mais significativos (CP3 $x$ CP2 $\times$ CP1)

A PCA também forneceu as coordenadas para os três primeiros componentes principais gerados para as 41 amostras de sedimentos aquáticos coletada.

A partir dessas coordenadas, podemos construir gráficos bidimensionais, $\mathrm{CP} 1 \times \mathrm{CP} 2, \mathrm{CP} 1 \times \mathrm{CP} 3, \mathrm{CP} 2 \times \mathrm{CP} 3$, ou tridimensionais, com os três $\mathrm{CPs}$, que representam a distribuição dos sedimentos explicada pelos componentes principais mais significativos.

Observando-se a distribuição espacial dos pontos de coleta no gráfico tridimensional (Figura 2b), CP3 x CP2 x CP1, verificou-se um agrupamento principal obtido pelo componente principal 1 , o qual concentra informações a respeito das concentrações de $\mathrm{Al}, \mathrm{Fe}$, $\mathrm{Cr}, \mathrm{Zn} \mathrm{Ni}, \mathrm{Co}, \mathrm{Pb}$ e $\mathrm{Hg}$. Esse agrupamento vai se deslocando para valores mais elevados do CP-1, de acordo com o aumento da contaminação no sistema.

Entretanto, podemos verificar que três pontos (4, 8 e 9) estão bastante afastados do agrupamento principal. Analisando-se os resultados obtidos para essas amostras (Tabela 3), verificamos que nos pontos 4 e 8 os sedimentos apresentaram um nível de contaminação para alguns elementos $(\mathrm{Hg}, \mathrm{Zn}, \mathrm{Pb})$ muito acima dos outros pontos de coleta e quase todos acima do PEL e, também, apresentaram concentração de Hg acima do ERM. Analisando-se também o ponto 9, que apresentou um grande afastamento do agrupamento principal, devido à influência do CP-3 que apresentou uma maior correlação com o elemento $\mathrm{Cd}(0,701)$ e portanto, uma maior concentração de informações a respeito desse elemento (Figura $2 \mathrm{a}$ ), verificou-se que esse ponto apresentou valor 2 vezes acima do TEL e também acima do ERL para o Cd. Também foi observado que outros pontos apresentaram certo afastamento do agrupamento principal: o ponto $7 \mathrm{com}$ um valor $\mathrm{Hg}$ acima do $>$ PEL e do $>$ ERM, os teores de Ni e Zn $>$ TEL e $>$ ERL e os teores de $\mathrm{Cr}$ e $\mathrm{Pb}>\mathrm{TEL}$; o ponto 5 com um valor acima do PEL para o Zn, o teor de Ni > TEL e > ERL e os teores de Cd e Hg > TEL; o ponto 6 com teores de $\mathrm{Ni}, \mathrm{Cd}$ e $\mathrm{Hg}>\mathrm{TEL}$ e $\mathrm{Hg}>$ ERL; o ponto 24 com os teores de $\mathrm{Cr}, \mathrm{Zn}, \mathrm{Ni}, \mathrm{Cd}>\mathrm{TEL}$ e Ni $>$ ERL; o ponto $32 \mathrm{com}$ teores de $\mathrm{Cr}$, Ni e $\mathrm{Cd}>\mathrm{TEL}$ e $\mathrm{Ni}>\mathrm{ERL}$; o ponto $33 \mathrm{com}$ teores de $\mathrm{Ni}$ $>$ TEL e $>$ ERL e o ponto 41 com teores de Ni e Hg $>$ TEL e $>$ ERL. Essa distribuição indica que nesses locais de amostragem os sedimentos são mais críticos em relação à contaminação por metais e devem ser estudados com maior cuidado.

\section{Análise de clusters hierárquicos (HCA)}

A Figura 3a mostra o dendograma relativo à similaridade entre as variáveis. Os ramos horizontais correspondem às variáveis e os números no topo da Figura indicam o índice de dissimilaridade, numa escala que vai de 0 (identidade) a 25 (máxima dissimilaridade entre 
essas variáveis). Podemos observar a formação de dois grupos separados pela máxima dissimilaridade. O grupo 1 é formado pelos elementos $\mathrm{Al}, \mathrm{Fe}, \mathrm{Ni}$, Co e $\mathrm{Cr}$, que tiveram um comportamento similar, apresentando os maiores níveis no canal de Piaçagüera, local impactado pelas atividades industriais. O segundo grupo, formado pelos elementos $\mathrm{Zn}, \mathrm{Hg}, \mathrm{Pb}$ e Cd pode ser subdividido em 2 subgrupos: o grupo 2-A, formado pelos elementos $\mathrm{Zn}, \mathrm{Hg}$ e $\mathrm{Pb}$ cujo comportamento similar indica uma influência causada pelas atividades industriais e portuárias nesses pontos e o grupo 2-B, formado pelo elemento $\mathrm{Cd}$ que apresentou maior similaridade com o grupo 2-A que com o grupo-1, porém, apresentou uma certa dissimilaridade com o grupo 2-A devido à maior concentração de $\mathrm{Cd}$ encontrada no ponto 9 , próximo a depósitos de resíduos sólidos domésticos (lixão).

a)

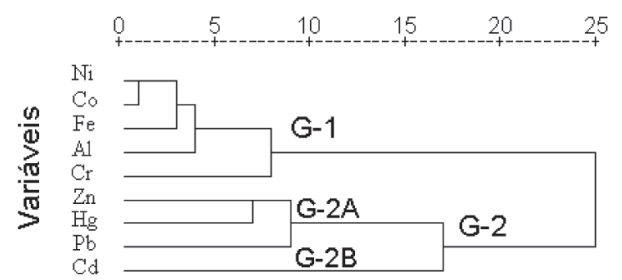

b)

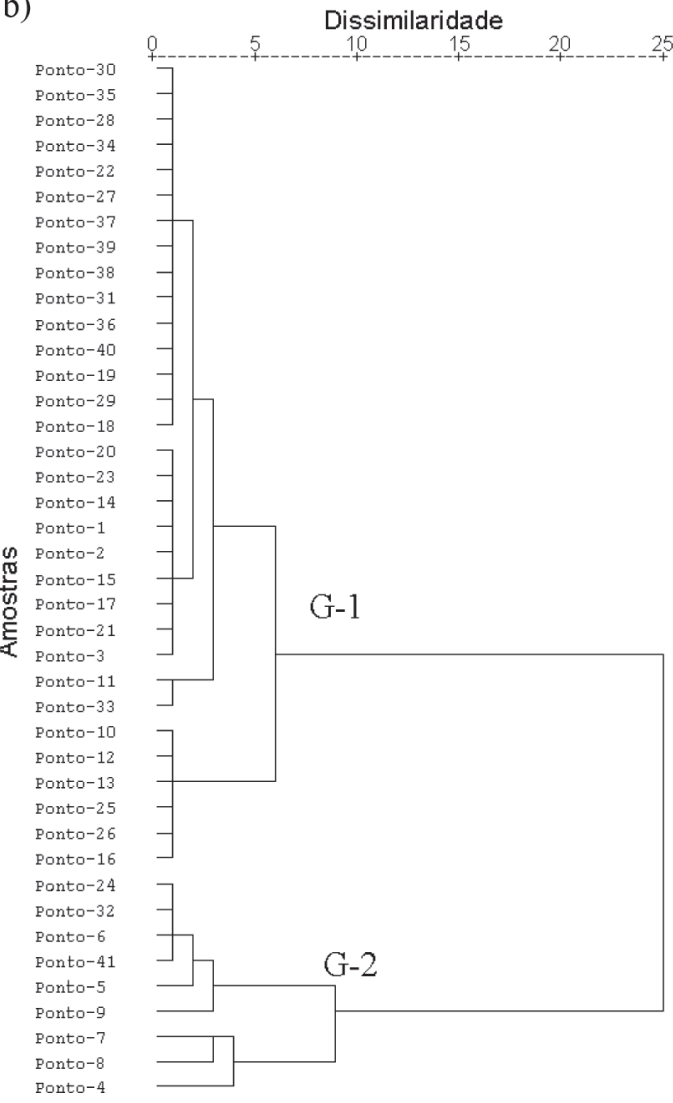

Figura 3. Dendogramas obtidos para as variáveis (a) e para as amostras (b) coletadas entre 1998/2000 usando o método Ward, após a normalização dos dados originais por Z-score. A distância Euclidiana quadrada foi usada para a medida de distância

A Figura $3 b$ mostra o dendograma relativo às amostras de sedimentos coletadas entre 1998/2000. Nessa figura podemos observar a separação dos pontos de coleta em dois grupos pela maior dissimilaridade entre a composição química das amostras.

A caracterização desses grupos foi feita pela média e desvio padrão de cada um dos elementos analisados. Observou-se que o grupo B, que contém 10 amostras, apresentou os elementos com concentração média de 1,7 a 4,6 vezes superiores aos elementos do grupo A (contendo 31 amostras), sugerindo que o grupo B compreende as amostras de sedimentos mais críticas em relação à contaminação. Essas amostras do grupo B foram coletadas em pontos localizados próximos às atividades industriais, portuárias e sob influência do emissário submarino de Santos, enquanto que o grupo A agrupa as amostras de sedimentos coletadas em pontos considerados como não contaminados.

Na Figura 3b, também podemos verificar que o grupo B representado pelas amostras coletadas em pontos mais críticos em relação à contaminação ainda pode ser dividido em dois subgrupos, um deles contendo os pontos (4, 7 e 8$)$ que apresentaram os sedimentos com as concentrações muito acima dos outros pontos de coleta para os elementos ( $\mathrm{Hg}, \mathrm{Zn}$ e $\mathrm{Pb})$, quase todos acima do PEL e todos com concentração de $\mathrm{Hg}$ acima do ERM. Verificou-se, finalmente, que os resultados obtidos pela HCA foram bastante próximos aos resultados obtidos pela PCA.

\section{Normalização}

Extrapolação da curva de regressão

A extrapolação da curva de regressão foi feita pela construção de gráficos representando a relação entre a concentração dos elementos $\mathrm{Cr}, \mathrm{Zn}, \mathrm{Pb}, \mathrm{Hg}, \mathrm{Fe}, \mathrm{Cd}$, Co e $\mathrm{Zn}$ versus o teor de Al. As Figuras 4 e 5 mostram exemplos desses gráficos para os elementos $\mathrm{Cr}, \mathrm{Hg}, \mathrm{Zn}, \mathrm{Co}$, $\mathrm{Ni}$ e $\mathrm{Pb}$. Para a construção desses gráficos foi necessária a remoção dos pontos que supostamente apresentaram contaminações (altas concentrações), para a definição da linha sólida, que representa a regressão linear, e as linhas pontilhadas, que representam o intervalo de $95 \%$ de confiança ( 2 vezes os valores dos desvios padrões). Em seguida, os pontos representando as possíveis áreas contaminadas foram, também, plotados no gráfico ${ }^{26}$. Todas as amostras que ficaram dentro do intervalo de confiança podem ser caracterizadas como tendo concentração natural dos metais, enquanto que as amostras fora do intervalo de confiança podem ser consideradas contaminadas.

\section{Fator de enriquecimento}

$\mathrm{O}$ impacto antropogênico foi quantificado pelo cálculo do Fator de Enriquecimento (EF) de acordo com a seguinte equação: ([Metal $] / \mathrm{Al}(\%)) /\left([\mathrm{Metal}] / \mathrm{Al}_{\text {background }}(\%)\right)$. Os valores de $[\mathrm{Metal}] / \mathrm{Al}_{\text {background }}$ foram obtidos pela média da razão dos pontos caracterizados como tendo concentração normal dos metais, ou seja, das amostras que ficaram dentro da banda de $95 \%$ de confiança obtidos pela extrapolação da curva de regressão.

Os valores de EF calculados para os metais que ficaram na faixa de $0,5 \leq \mathrm{EF} \leq 1,5$ sugerem que os traços dos metais presentes nos sedimentos podem ser devidos à composição geológica do material ou à influência de processos climáticos naturais ${ }^{39}$. Os pontos que apresentaram $\mathrm{EF}>1,5$ indicam a evidência de que uma importante proporção do metal provém de outras fontes ${ }^{40}$, sugerindo contaminação ambiental por esses metais e indicando as regiões do sistema estuarino com maior grau de contaminação.

Comparando-se os resultados obtidos pelas duas técnicas de normalização (EF e extrapolação da curva de regressão), podem-se observar as vantagens e desvantagens de cada uma dessas técnicas.

Foi verificado que a principal desvantagem da normalização por EF ocorreu nos pontos 12 e 13, onde a maioria dos elementos analisados $(\mathrm{Hg}, \mathrm{Pb}, \mathrm{Zn}, \mathrm{Ni}, \mathrm{Co}$ e $\mathrm{Fe})$ apresentou elevados valores para $\mathrm{EF}(\mathrm{EF}>1,5)$, valores esses que indicam contaminação. Porém, verificou-se que isto ocorreu devido à baixa concentração de Al (elemento normalizador) encontrada nesses pontos. Portanto, a 

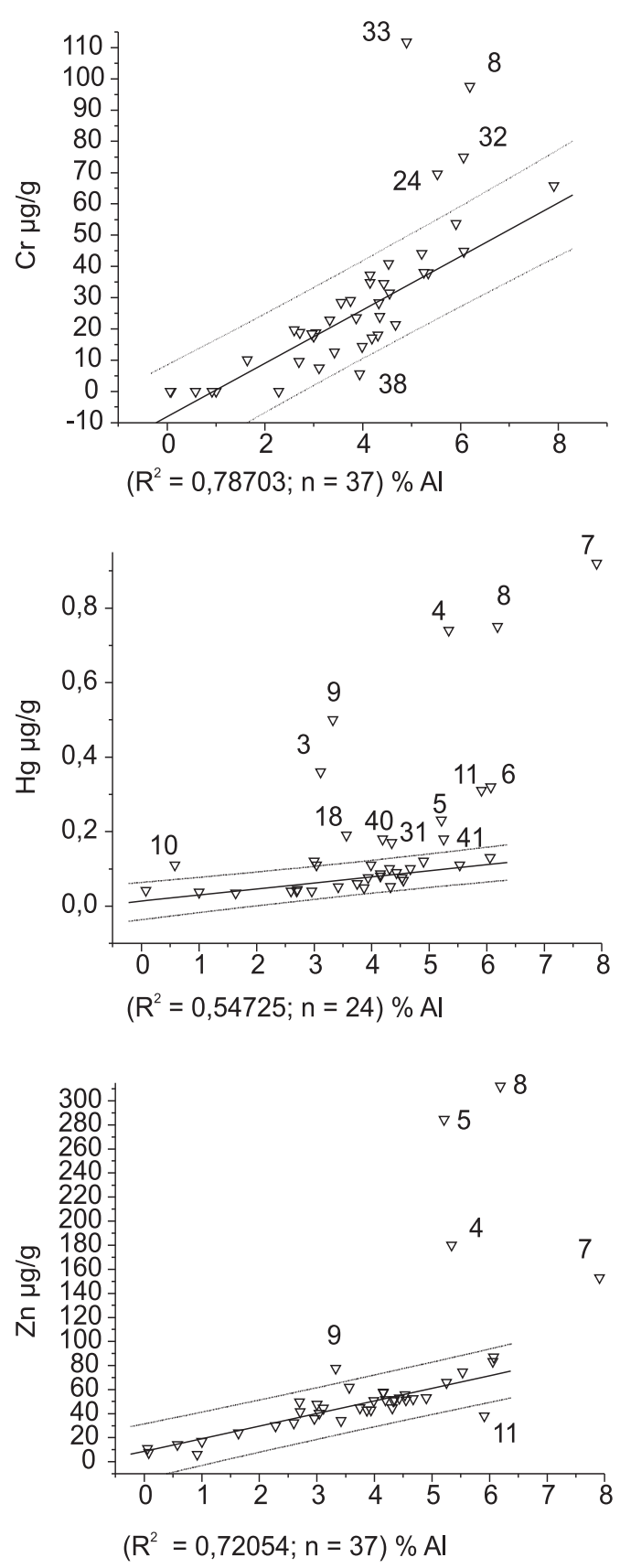

Figura 4. Gráficos representando a relação entre a concentração dos elementos $\mathrm{Cr}$, $\mathrm{Hg}$ e $\mathrm{Zn}$ versus o teor de Al. A linha sólida representa a regressão linear, enquanto as linhas pontilhadas representam o intervalo de $95 \%$ de confiança (2 vezes os valores de desvio padrão); amostras fora do intervalo de confiança são consideradas contaminadas

técnica mais adequada para esses pontos é a normalização pela extrapolação da curva de regressão.

Também foram observadas algumas desvantagens da normalização pela curva de regressão (Figuras 4 e 5). Os elementos Zn, Ni e Co (ponto 11) apareceram fora do intervalo de confiança da curva de regressão, o que indicaria amostra contaminada. Entretanto, quando se analisa a normalização por EF, verifica-se que esses 3 elementos apresentaram $\mathrm{EF}<1,5$, o que não indica contaminação, como, também, os teores estão bem abaixo dos valores limites de TEL e ERM (Tabela 3), os quais poderiam indicar contaminação. Portanto, para os elementos $\mathrm{Zn}$, Ni e Co no ponto 11 a normalização por
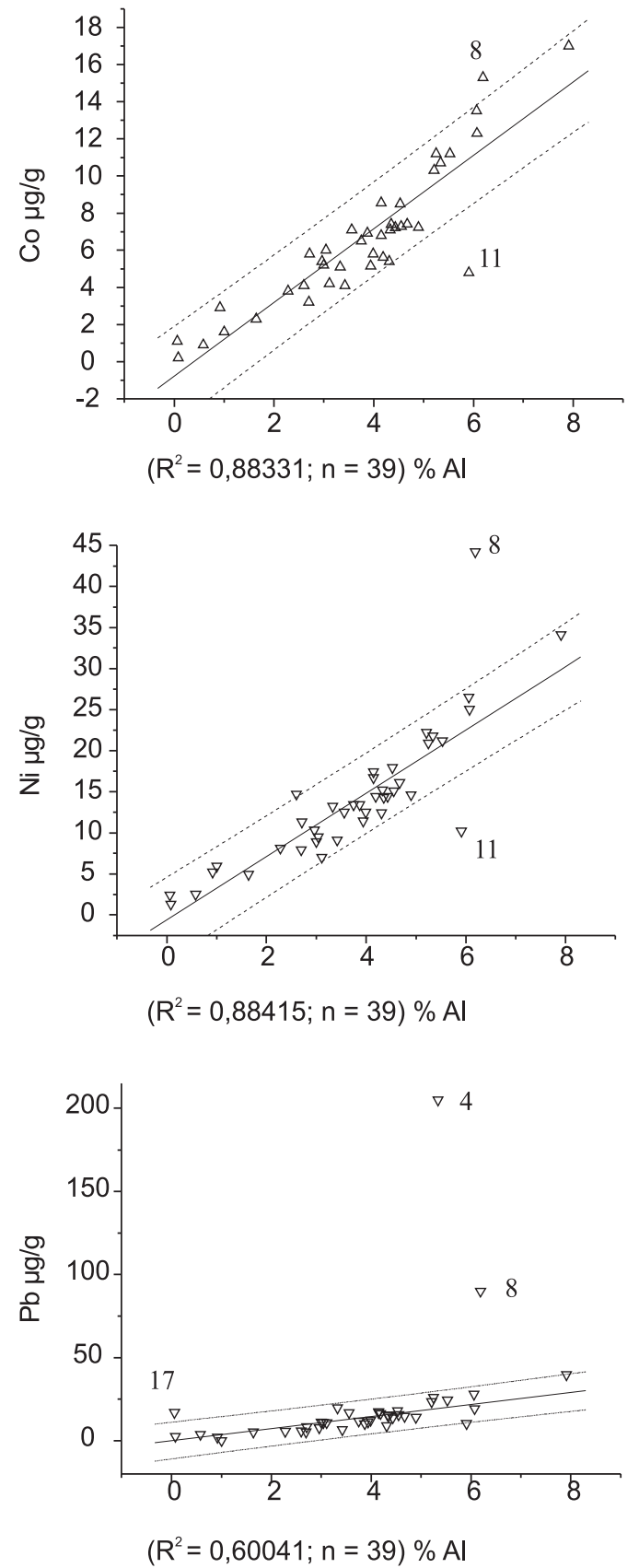

Figura 5. Gráficos representando a relação entre a concentração dos elementos Co, Ni e Pb versus o teor de Al. A linha sólida representa a regressão linear, enquanto as linhas pontilhadas representam o intervalo de $95 \%$ de confiança (2 vezes os valores de desvio padrão); amostras fora do intervalo de confiança são consideradas contaminadas

EF é mais adequada que a extrapolação da curva de regressão.

Também o ponto 17 apareceu como contaminado pela extrapolação da curva de regressão para o elemento $\mathrm{Pb}$. Entretanto, pelo valor de $\mathrm{EF}=0,6$ do $\mathrm{Pb}$, temos que a sua concentração é normal no sedimento; também se verificou que a concentração de $\mathrm{Pb}$ nesse ponto ficou abaixo dos limites $P E L$ e $E R L$.

A partir dessas observações, foram eliminadas as desvantagens de cada uma das técnicas de normalização. Chegou-se, assim, aos elementos cujos teores são caracterizados como anômalos e, portanto, considerados como contaminantes dos sedimentos (Tabela 4).

Analisando-se a Tabela 4, verifica-se que 13 pontos apresentaram 
Tabela 4. Comparação entre os dois procedimentos de normalização utilizados e os valores de TEL, PEL, ERL e ERM.

\begin{tabular}{|c|c|c|c|c|c|c|c|}
\hline \multicolumn{8}{|c|}{ Pontos com amostras contaminadas } \\
\hline Elementos & $\begin{array}{l}\text { Normalização (1) } \\
\text { Fora da banda } \\
95 \% \text { confiança }\end{array}$ & $\begin{array}{c}\text { Normalização (2) } \\
\qquad \mathrm{EF}>1,5\end{array}$ & $\begin{array}{c}\text { Normalização, } \\
\text { eliminando as } \\
\text { deficiências }\end{array}$ & $>T E L$ & $>P E L$ & $>E R L$ & $>E R M$ \\
\hline $\mathrm{Hg}$ & $\begin{array}{c}3,4,5,6,7,8,9 \\
10,11,18,31 \\
40 \text { e } 41\end{array}$ & $\begin{array}{l}3,4,7,8 \\
9,10 \text { e } 12\end{array}$ & $\begin{array}{c}3,4,5,6 \\
7,8,9 \\
40 \text { e } 41\end{array}$ & $\begin{array}{c}3,5,6,9 \\
10,11,18 \\
31,40 \text { e } 41\end{array}$ & 4,7 e 8 & $\begin{array}{c}3,5,6,9 \\
11,18,31 \\
40 \text { e } 41\end{array}$ & 4,7 e 8 \\
\hline $\mathrm{Pb}$ & 4,8 e 17 & $4,8,10,12$ e 13 & 4 e 8 & 7 & 4 e 8 & 4 e 8 & nenhum \\
\hline $\mathrm{Zn}$ & $\begin{array}{l}4,5,7,8 \\
\quad 9 \text { e } 11\end{array}$ & $\begin{array}{c}4,5,8,9 \\
12 \text { e } 13\end{array}$ & $4,5,7$ e 8 & 4 e 7 & 5 e 8 & $4,5,7,8$ & nenhum \\
\hline $\mathrm{Ni}$ & 8 e 11 & 8,12 e 13 & 8 & $\begin{array}{l}4,5,6,7,22, \\
24,27,32,34, \\
\quad 36 \text { e } 41\end{array}$ & 8 & $\begin{array}{l}4,5,6,7 \\
8,24, \text { e } 32\end{array}$ & nenhum \\
\hline Co & 8 e 11 & 13 & nenhum & Lne & Lne & Lne & Lne \\
\hline $\mathrm{Cr}$ & $\begin{array}{c}8,24,32 \\
33 \text { e } 38\end{array}$ & $\begin{array}{c}8,24 \\
32 \text { e } 33\end{array}$ & $\begin{array}{c}8,24 \\
32 \text { e } 33\end{array}$ & $\begin{array}{c}7,8,11,24 \\
32 \text { e } 33\end{array}$ & nenhum & 8 e 33 & nenhum \\
\hline $\mathrm{Cd}$ & 9 & 9 & 9 & $4,5,6,8$ e 9 & nenhum & 9 & nenhum \\
\hline $\mathrm{Fe}$ & 7,8 e 41 & $8,10,12$ e 13 & 7 e 8 & Lne & Lne & Lne & Lne \\
\hline
\end{tabular}

Lne: Limite não estabelecido

contaminação para o elemento $\mathrm{Hg}$ pela normalização, resultado bastante próximo ao encontrado utilizando-se os 2 critérios que avaliam a qualidade dos sedimentos, o canadense, com 12 pontos acima dos limites TEL e PEL, e o americano, também com 12 pontos acima dos limites ERL e ERM. O elemento $\mathrm{Hg}$ foi o único, entre todos os elementos analisados nos sedimentos, que apresentou valores acima do ERM para os pontos 4, 7 e 8 . Esses dados sugerem que o Hg é um dos contaminantes mais preocupantes do estuário, apresentando um padrão diferenciado, pois, atualmente suas concentrações máximas não parecem estar aumentando, entretanto, ele se encontra em teores considerados danosos para a biota na maior parte do estuário. Esses resultados estão de acordo com os encontrados por Horvat et al. ${ }^{41}$ no golfo de Trieste, entre Itália e Eslovênia, onde após 10 anos da desativação de uma mineradora que provocava extensa contaminação dos sedimentos por $\mathrm{Hg}$, os níveis ainda estavam altos com um aumento da área contaminada. Outra preocupação é o fato de que o $\mathrm{Hg}$ contido nos sedimentos pode ser metilado produzindo o metilmercúrio (MeHg), uma das mais tóxicas formas do $\mathrm{Hg}$. Os níveis de $\mathrm{MeHg}$ nos sedimentos são controlados por uma competição simultânea entre metilação e desmetilação ${ }^{42}$. Normalmente o $\mathrm{MeHg}$ representa cerca de $1,5 \%$ da concentração de $\mathrm{Hg}$ total nos sedimentos. Entretanto, esse composto organometálico pode ser incorporado pela biota aquática, entrando na cadeia alimentar onde sofre uma biomagnificação ${ }^{43}$, chegando a representar mais que $85 \%$ do $\mathrm{Hg}$ total presente nos peixes ${ }^{44}$. Desse modo, a ingestão de peixes é uma das principais vias para a intoxicação humana ${ }^{45}$.

Para o elemento $\mathrm{Pb}$, os pontos 4 e 8 , identificados pela normalização como contaminados, foram também os pontos com teores acima do PEL e do ERL.

Para o elemento $\mathrm{Zn}$, os pontos 4, 5, 7 e 8, identificados pela normalização como contaminados, foram os mesmos encontrados pelos dois critérios que definem a qualidade dos sedimentos, com os pontos 4 e 7 com os teores de Zn acima do TEL, os 5 e 8 acima do PEL e os 4, 5, 7 e 8 acima do ERL.

Para o elemento Ni, o único ponto identificado pela normalização como contaminado, foi o 8, também o único com o teor de $\mathrm{Ni}$ acima do PEL e um dos sete pontos com os teores acima do ERL, porém, 2 vezes maior que o ERL, bem próximo do ERM.

O elemento Co não apresentou nenhum ponto identificado como contaminado pela normalização. Também não existem limites para o Co nos dois critérios, canadense e americano, que indicam a qualidade dos sedimentos. Portanto, conclui-se que esse elemento faz parte da constituição natural dos sedimentos dessa área ou é resultado de processos climáticos naturais.

$\mathrm{O}$ elemento $\mathrm{Cr}$ apresentou 4 pontos identificados pela normalização como contaminados, 6 pontos com teores acima do TEL e apenas 2 pontos com teores acima do ERL .

$\mathrm{O}$ elemento $\mathrm{Cd}$ apresentou um único ponto identificado como contaminado, pela normalização, o ponto 9 , e também um ponto (ponto 9) com valor acima do ERL, e 5 pontos (4, 5, 6, 8 e 9) com valores acima do TEL. Porém, o ponto 9 apresentou um valor cerca de 2 vezes maior que o TEL.

O elemento Fe apresentou apenas dois pontos (7 e 8) contaminados pela normalização, localizados no canal de Piaçagüera, região sob influência de uma Siderúrgica que produz aço, portanto com potencial de emissão de Fe em seus efluentes. Entretanto, não se pode afirmar se sua origem é industrial ou natural da geologia do sedimento ${ }^{4}$.

\section{CONCLUSÕES}

A normalização dos dados com o teor de Al, bem como a utilização de duas diferentes técnicas quimiométricas, PCA e a HCA, mostraram sua utilidade na avaliação da contaminação por elementos metálicos dos sedimentos na região estudada e apresentaram resultados coerentes com os critérios canadense e americano de avaliação da qualidade dos sedimentos.

Este trabalho identifica as áreas do Estuário de Santos - São Vicente que apresentam sedimentos com maior grau de contaminação por elementos metálicos. Os dados analíticos apresentados, somados aos já existentes, podem contribuir para um futuro estabelecimento, pela legislação ambiental brasileira, de critérios nacionais para avaliar a qualidade de sedimentos. Os resultados aqui apresentados, também podem contribuir para alertar quanto aos cuidados ainda necessários a serem tomados na área de segurança química das indústrias de Cubatão, das atividades portuárias, das dragagens do canal do porto, dos efluentes domésticos e lixões. Com isso, pode-se reduzir o impacto ambiental dos contaminantes e, conseqüientemente, o risco à saúde publica.

\section{MATERIAL SUPLEMENTAR}

O material suplementar descrito a seguir está disponível gratuitamente em http://quimicanova.sbq.org.br, na forma de arquivo PDF: 
Figura 1S: Gráficos representando a relação entre a concentração dos elementos $\mathrm{Cd}$ e Fe versus o teor de Al. A linha sólida representa a regressão linear, enquanto as linhas pontilhadas representam o intervalo de $95 \%$ de confiança (2 vezes os valores de desvio padrão), amostras fora do intervalo de confiança são consideradas contaminadas.

Tabela 1S: Principais correlações de Pearson (r), entre duas variáveis dos sedimentos do estuário ( $\mathrm{n}=$ número de amostras $\geq \mathrm{LQ}$ ).

Tabela 2S: Caracterização dos grupos definidos pela composição química.

Tabela 3S: Fator de enriquecimento (EF) para os elementos metálicos nos sedimentos do estuário de Santos - São Vicente, coletados entre 1998/2000.

\section{AGRADECIMENTOS}

À FAPESP (Processo 98/00808-6) pelo suporte financeiro.

\section{REFERÊNCIAS}

1. Companhia de Tecnologia de Saneamento Ambiental - CETESB Qualidade das águas interiores do Estado de São Paulo, São Paulo, 1999.

2. Pereira, M. E.; Duarte, A. C.; Millward, G. E.; Abreu, S. N.; Vale, C.; Water Sci. Techol. 1998, 37, 125.

3. Soares, H. M. V. M.; Boaventura, R. A.; Machado, A. A. S. C.; Esteves da Silva, J. C. G.; Environ. Pollut. 1999, 105, 311.

4. Abessa, D. M. S.; Tese de Doutorado, Universidade de São Paulo, Brasil, 2002.

5. Chapman, P. M.; Mar. Pollut. Bull. 2002, 44, 7.

6. Companhia de Tecnologia de Saneamento Ambiental - CETESB; Sistema Estuarino Santos e São Vicente, São Paulo, 2001.

7. Silva, P. S. C.; Mazzilli, B. P.; Favaro, D. I. T.; J. Radioanal. Nucl. Chem. 2006, 269, 739 .

8. Silva, N. C.; Fernandes, E. A. N.; Cipriani, M.; Taddei, M. H. T.; J. Radioanal. Nucl. Chem. 2001, 249, 251.

9. Bolivar, J. P.; Garcia-Tenorio, R; Ma, J. L.; Vaca, F.; Environ. Int. 2002, $27,639$.

10. Tommasi, L. R.; Tese de Livre-Docência, Universidade de São Paulo, Brasil, 1978.

11. Harari, J.; Mesquita, A. R.; Marone, E.; França, C. A. S.; Camargo, R.; Pereira, J. E. R.; Adão, C. J. G. P.; Sá Junior, I. L.; Technical report of the project "Flow Measurements in the Bay of Santos", FUNDESPA: São Paulo, 1990.

12. Luiz-Silva, W.; Matos, R. H. R.; Kristosch, G. C.; Quim. Nova 2002, 25, 753.

13. Siqueira, G. W.; Braga, E. S.; Pereira, S. F. P.; Silva, E. D.; Rev. Esc. Minas 2005, 58, 309 .

14. Abessa, D. M. S; Carr, R. S.; Rachid, B. R. F.; Sousa, E. C. P. M.; Hortellani, M. A.; Sarkis, J. E. S.; Mar. Pollut. Bull. 2005, 50, 875.

15. Hortellani, M. A.; Sarkis, J. E. S.; Bonetti, J.; Bonetti, C.; J. Braz. Chem Soc. 2005, 16, 1140 .
16. Luiz-Silva, W.; Matos, R. H. R.; Kristosch, G. C.; Machado, W.; Quim. Nova 2006, 29, 256

17. Akagi, H.; Malm, O.; Kingo, Y.; Harada, M.; Branches, F. J. P.; Pfeifer, W. C.; Kato, H.; Sci. Total Envviron. 1995, 175, 85.

18. Fostier, A. H.; Ferreira, J. R.; de Andrade, M. O.; Quim. Nova 1995, 18, 425.

19. Krause, P.; Erbsloh, B.; Niedergesab, R.; Pepelnik, R.; Prange, A.; Fresenius J. Anal. Chem. 1995, 353, 3 .

20. Zar, J. H.; Biostatistical Analysis, $3^{\text {rd }}$ ed., Prentice-Hall:, New Jersey, 1996

21. MICROSOFT, "SPSS Base 10.0 Application Guid", manual de softweer, 1999.

22. Ferreira, M. M. C.; Antunes, A. M.; Melgo, M. S.; Volpe, P. L. O.; Quim. Nova 1999, 22, 724

23. Da Silva, M. C. M.; Honório, K. M.; Brigante, J.; Espíndola, E. L. G.; Vieira, E. M.; Gambardella, M. T. P.; da Silva, A. B. F.; J. Braz. Chem. Soc. 2005 , 16,1104

24. Latini, R. M.; Bellido, A. V.; Vasconcellos, M. B. A.; Dias Junior, O. F.; Quim. Nova 2001, 24, 724 .

25. Clark, M. W.; Davies-McConchie, F.; McConchie, D.; Birch, G. F.; Sci. Total Environ. 2000, 258, 149.

26. Aloupi, M.; Angelidis, M. O.; Environ. Pollut. 2001, 113, 211

27. Windom, H. L.; Schopp, S. J.; Calder, F. D.; Ryan, J. D.; Smith Jr., R. G.; Burney, L. C.; Lewis, F. G.; Rawlinson, C. H.; Environ. Sci. Technol. 1989, $23,314$.

28. Cox, M. E.; Preda, M.; Mar. Pollut. Bull. 2003, 46, 1615.

29. Cook, J. M.; Gardner, M. J.; Griffiths, A. H.; Jessep, M. A.; Ravenscroft, J. E.; Yates, R.; Mar. Pollut. Bull. 1997, 34, 637.

30. Instituto Nacional de Metrologia, Normalização e Qualidade Industrial (INMETRO); Orientações sobre Validação de Métodos de Ensaios Químicos, 2003.

31. MacDonald, D.; Carr, R. S.; Calder, F. D.; Long, E. R.; Ingersoll, C. G.; Ecotoxicology 1996, 5, 253.

32. Long, E. R.; MacDonald, D. D.; Smith, S. L.; Calder, F. D.; Environ. Manage. 1995, 19, 81 .

33. Much, A. P.; Vasconcelos, M. T. S. D.; Bordalo, A. A.; Environ. Pollut. 2003, 121,169

34. Resolução CONAMA n ${ }^{\circ} 344$, http://www.cprh.pe.gov.br/downloads/ reso344.doc, acessada em Março 2007.

35. Marins, R. V.; de Paula Filho, F. J.; Maia, S. R. R.; de Lacerda, L. D.; Marques, W. S.; Quim. Nova 2004, 27, 763.

36. Harbison, P.; Mar. Pollut. Bull. 1996, 17, 246.

37. Warnkers, K. W.; Gill, G. A.; Griffin, L. L.; Santschi, P. H.; Mar. Chem. 2001, 73, 215.

38. Scarmínio, I. S.; Tese de Doutorado, Universidade Estadual de Campinas, Brasil, 1989

39. Zhang, J.; Liu, C. L.; Estuarine, Coastal Shelf Sci. 2002, 54, 1051.

40. Feng, H.; Han, X.; Zhang, J.; Yu, L.; Mar. Pollut. Bull. 2004, 49, 910.

41. Horvat, M.; Covelli, S., Fraganeli, J.; Logar, M.; Mandic, V.; Rajar, R.; Sirca, A.; Sci. Total Environ. 1999, 237-238, 45.

42. Bisinoti, M. C.; Jardim, W. F.; Quim. Nova 2004, 27, 593.

43. Malm, O.; Branches, F. J. P.; Akagi, H.; Castro, M. B.; Pfeiffer, W. C.; Harada, M.; Bastos, W. R.; Kato, H.; Sci. Total Environ. 1995, 175, 127.

44. May, K.; Stoeppler, M.; Reising, K.; Toxicol. Environ. Chem. 1987, 13, 153.

45. Cai, Y.; Bayona, J. M.; J. Chromatogr., A 1995, 696, 113. 
AVALIAÇÃO DA CONTAMINAÇÃO POR ELEMENTOS METÁlICOS DOS SEDIMENTOS DO ESTUÁRIO SANTOS - SÃO VICENTE

\section{Marcos Antonio Hortellani* e Jorge E. S. Sarkis}

Centro de Química e Meio Ambiente, Instituto de Pesquisas Energéticas e Nucleares, Av. Prof. Lineu Prestes, 2242, 05508-000 São Paulo - SP, Brasil

\section{Denis M. S. Abessa}

Departamento de Biologia Marinha e Gerenciamento Costeiro, Campus do Litoral Paulista, Universidade Estadual Paulista, Praça Infante Dom Henrique, s/n, 011330-900 São Vicente - SP, Brasil

Eduinetty C. P. M. Sousa

Departamento de Oceanografia Biológica, Instituto Oceanográfico, Universidade de São Paulo, Praça do Oceanográfico, 191, 05508-900 São Paulo - SP, Brasil
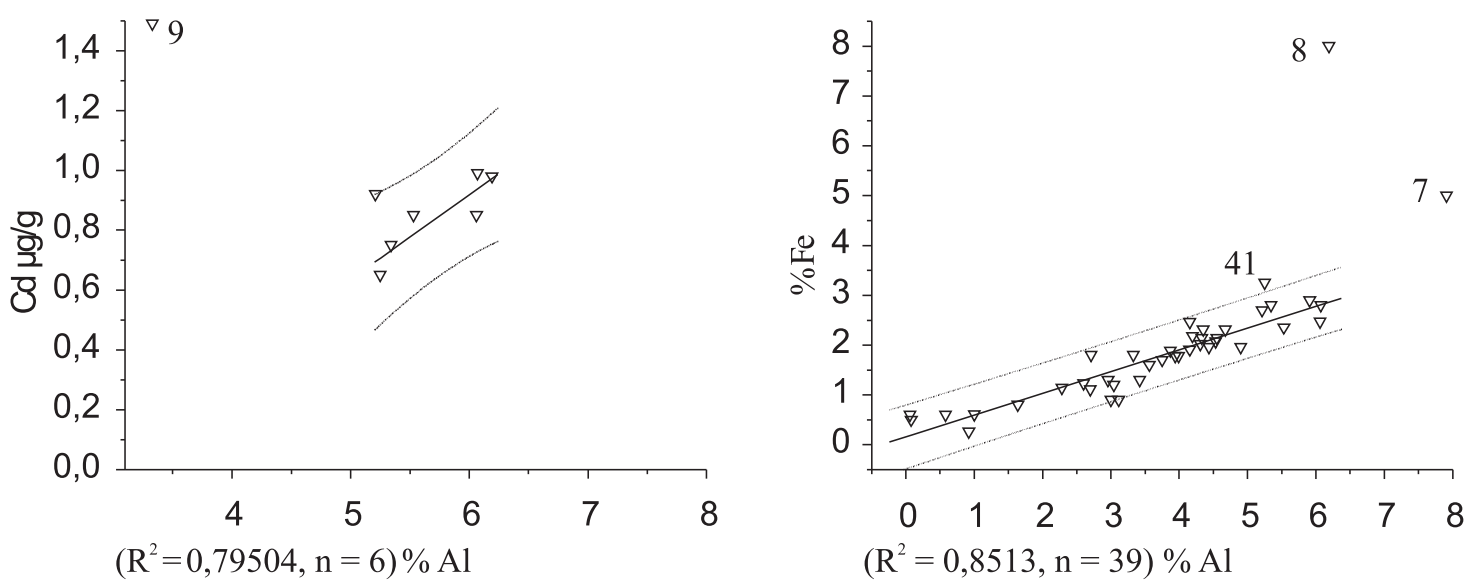

Figura 1S. Gráficos representando a relação entre a concentração dos elementos Cd e Fe versus o teor de Al. A linha sólida representa a regressão linear, enquanto as linhas pontilhadas representam o intervalo de $95 \%$ de confiança (2 vezes os valores de desvio padrão); amostras fora do intervalo de confiança são consideradas contaminadas

Tabela 1S. Principais correlações de Pearson (r), entre duas variáveis dos sedimentos do estuário (n = número de amostras $\geq$ LQ )

\begin{tabular}{|c|c|c|c|c|c|c|c|c|c|}
\hline & $\mathrm{Al}$ & $\mathrm{Fe}$ & $\mathrm{Cr}$ & $\mathrm{Zn}$ & $\mathrm{Ni}$ & $\mathrm{Co}$ & $\mathrm{Cd}$ & $\mathrm{Pb}$ & $\mathrm{Hg}$ \\
\hline $\mathrm{Al}$ & $\begin{array}{c}1 \\
(n=41)\end{array}$ & & & & & & & & \\
\hline $\mathrm{Fe}$ & $\begin{array}{l}0,771^{\mathrm{a}} \\
(\mathrm{n}=41)\end{array}$ & $\begin{array}{c}1 \\
(n=41)\end{array}$ & & & & & & & \\
\hline $\mathrm{Cr}$ & $\begin{array}{l}0,718^{a} \\
(n=35)\end{array}$ & $\begin{array}{l}0,657^{\mathrm{a}} \\
(\mathrm{n}=35)\end{array}$ & $\begin{array}{c}1 \\
(n=35)\end{array}$ & & & & & & \\
\hline $\mathrm{Zn}$ & $\begin{array}{l}0,595^{\mathrm{a}} \\
(\mathrm{n}=41)\end{array}$ & $\begin{array}{l}0,793^{\mathrm{a}} \\
(\mathrm{n}=41)\end{array}$ & $\begin{array}{l}0,513^{\mathrm{a}} \\
(\mathrm{n}=35)\end{array}$ & $\begin{array}{c}1 \\
(n=41)\end{array}$ & & & & & \\
\hline $\mathrm{Ni}$ & $\begin{array}{l}0,846^{a} \\
(n=41)\end{array}$ & $\begin{array}{l}0,992^{a} \\
(n=41)\end{array}$ & $\begin{array}{l}0,714^{a} \\
(n=35)\end{array}$ & $\begin{array}{l}0,801^{\mathrm{a}} \\
(\mathrm{n}=41)\end{array}$ & $\begin{array}{c}1 \\
(n=41)\end{array}$ & & & & \\
\hline $\mathrm{Co}$ & $\begin{array}{l}0,898^{\mathrm{a}} \\
(\mathrm{n}=41)\end{array}$ & $\begin{array}{l}0,827^{a} \\
(n=41)\end{array}$ & $\begin{array}{l}0,708^{a} \\
(n=35)\end{array}$ & $\begin{array}{l}0,710^{\mathrm{a}} \\
(\mathrm{n}=41)\end{array}$ & $\begin{array}{l}0,951^{a} \\
(n=41)\end{array}$ & $\begin{array}{c}1 \\
(n=41)\end{array}$ & & & \\
\hline $\mathrm{Cd}$ & $\begin{array}{c}-0,802^{\mathrm{a}} \\
(\mathrm{n}=9)\end{array}$ & $\begin{array}{c}-0,267^{\text {ns }} \\
(\mathrm{n}=9)\end{array}$ & $\begin{array}{c}-0,308^{\mathrm{ns}} \\
(\mathrm{n}=9)\end{array}$ & $\begin{array}{c}-0,050^{\mathrm{ns}} \\
(\mathrm{n}=9)\end{array}$ & $\begin{array}{c}-0,390^{\mathrm{ns}} \\
(\mathrm{n}=9)\end{array}$ & $\begin{array}{c}-0,750^{\mathrm{b}} \\
(\mathrm{n}=9)\end{array}$ & $\begin{array}{c}1 \\
(n=9)\end{array}$ & & \\
\hline $\mathrm{Pb}$ & $\begin{array}{l}0,380^{\mathrm{b}} \\
(\mathrm{n}=40)\end{array}$ & $\begin{array}{l}0,483^{a} \\
(n=40)\end{array}$ & $\begin{array}{l}0,299^{\text {ns }} \\
(n=35)\end{array}$ & $\begin{array}{l}0,606^{a} \\
(n=40)\end{array}$ & $\begin{array}{l}0,502^{\mathrm{a}} \\
(\mathrm{n}=40)\end{array}$ & $\begin{array}{l}0,474^{a} \\
(n=40)\end{array}$ & $\begin{array}{c}-0,192^{\text {ns }} \\
(n=9)\end{array}$ & $\begin{array}{c}1 \\
(n=40)\end{array}$ & \\
\hline $\mathrm{Hg}$ & $\begin{array}{l}0,564^{\mathrm{a}} \\
(\mathrm{n}=38)\end{array}$ & $\begin{array}{l}0,702^{a} \\
(n=38)\end{array}$ & $\begin{array}{l}0,414^{b} \\
(n=35)\end{array}$ & $\begin{array}{l}0,688^{\mathrm{a}} \\
(\mathrm{n}=38)\end{array}$ & $\begin{array}{l}0,658^{a} \\
(n=38)\end{array}$ & $\begin{array}{l}0,614^{a} \\
(n=38)\end{array}$ & $\begin{array}{c}-0,189^{\text {ns }} \\
(n=9)\end{array}$ & $\begin{array}{l}0,675^{a} \\
(n=37)\end{array}$ & $\begin{array}{c}1 \\
(n=38)\end{array}$ \\
\hline
\end{tabular}

${ }^{a}$ Correlação altamente significante com $\mathrm{p}<0,01 .{ }^{\mathrm{b}}$ Correlação significante com $\mathrm{p}<0,05$. ${ }^{\text {ns }}$ Correlação não significante com $\mathrm{p}>0,05$ 
Tabela 2S. Caracterização dos grupos definidos pela composição química

\begin{tabular}{lcc}
\hline Elemento & \multicolumn{2}{c}{ Média \pm desvio } \\
& Grupo-A & Grupo-B \\
\hline $\mathrm{Al}(\%)$ & $3,20 \pm 1,16$ & $5,58 \pm 1,16$ \\
$\mathrm{Fe}(\%)$ & $1,53 \pm 0,67$ & $3,30 \pm 1,46$ \\
$\mathrm{Cr}\left(\mu \mathrm{g} \mathrm{g}^{-1}\right)$ & $19,5 \pm 12,5$ & $60,7 \pm 28,4$ \\
$\mathrm{Zn}\left(\mu \mathrm{g} \mathrm{g}^{-1}\right)$ & $40,0 \pm 15,5$ & $137,0 \pm 93,9$ \\
$\mathrm{Ni}\left(\mu \mathrm{g} \mathrm{g}^{-1}\right)$ & $10,9 \pm 4,9$ & $24,4 \pm 9,1$ \\
$\mathrm{Co}\left(\mu \mathrm{g} \mathrm{g}^{-1}\right)$ & $5,1 \pm 2,2$ & $11,4 \pm 3,5$ \\
$\mathrm{Cd}\left(\mu \mathrm{g} \mathrm{g}^{-1}\right)$ & $0,50 \pm 0,00$ & $0,84 \pm 0,30$ \\
$\mathrm{~Pb}\left(\mu \mathrm{g} \mathrm{g}^{-1}\right)$ & $10,6 \pm 5,0$ & $48,9 \pm 58,9$ \\
$\mathrm{Hg}\left(\mu \mathrm{g} \mathrm{g}^{-1}\right)$ & $0,09 \pm 0,08$ & $0,40 \pm 0,31$ \\
\hline
\end{tabular}

Tabela 3S. Fator de enriquecimento (EF) para os elementos metálicos nos sedimentos do estuário de Santos -São Vicente, coletados entre $1998 / 2000$

\begin{tabular}{|c|c|c|c|c|c|c|c|c|}
\hline Pontos & $\begin{array}{l}\mathrm{EF} \\
\mathrm{Hg}\end{array}$ & $\begin{array}{l}\mathrm{EF} \\
\mathrm{Pb}\end{array}$ & $\begin{array}{l}\mathrm{EF} \\
\mathrm{Zn}\end{array}$ & $\begin{array}{l}\mathrm{EF} \\
\mathrm{Ni}\end{array}$ & $\begin{array}{l}\text { EF } \\
\text { Co }\end{array}$ & $\begin{array}{l}\mathrm{EF} \\
\mathrm{Cr}\end{array}$ & $\begin{array}{l}\mathrm{EF} \\
\mathrm{Cd}\end{array}$ & $\begin{array}{l}\mathrm{EF} \\
\mathrm{Fe}\end{array}$ \\
\hline 1 & 0,9 & 0,9 & 0,8 & 0,8 & 0,9 & 1,0 & $-*$ & 0,8 \\
\hline 2 & 1,0 & 0,9 & 1,0 & 0,7 & 0,8 & 0,9 & $-*_{-}$ & 0,6 \\
\hline 3 & 2,8 & 0,8 & 0,9 & 0,6 & 0,6 & 0,4 & $-*$ & 0,6 \\
\hline 4 & 3,4 & 9,1 & 2,1 & 1,0 & 0,9 & 1,1 & 1,0 & 1,1 \\
\hline 5 & 1,1 & 1,1 & 3,4 & 1,1 & 0,9 & 1,3 & 1,2 & 1,1 \\
\hline 6 & 1,3 & 0,8 & 0,9 & 1,0 & 0,9 & 1,2 & 1,1 & 0,9 \\
\hline 7 & 2,8 & 1,2 & 1,2 & 1,1 & 1,0 & 1,3 & $-*_{-}$ & 1,3 \\
\hline 8 & 3,0 & 3,5 & 3,2 & 1,8 & 1,1 & 2,5 & 1,1 & 2,7 \\
\hline 9 & 3,7 & 1,4 & 1,5 & 1,0 & 0,7 & 1,1 & 3,1 & 1,1 \\
\hline 10 & 4,6 & 1,5 & 1,5 & 1,1 & 0,7 & $-*_{-}$ & $-*_{-}$ & 2,3 \\
\hline 11 & 1,3 & 0,4 & 0,4 & 0,4 & 0,4 & 1,4 & $-*_{-}$ & 1,0 \\
\hline 12 & 12,8 & 7,4 & 6,0 & 4,1 & 1,1 & $-*_{-}$ & $-*$ & 13,6 \\
\hline 13 & $-*$ & 67,4 & 11,5 & 10,0 & 8,4 & $-*_{-}$ & $-*$ & 21,6 \\
\hline 14 & 0,4 & 0,5 & 0,6 & 0,7 & 0,5 & 0,6 & $-*_{-}$ & 0,8 \\
\hline $15(4)^{*}$ & 0,4 & 0,7 & 1,0 & 1,0 & 1,0 & 1,1 & $-*_{-}$ & 1,4 \\
\hline 16 & 0,5 & 0,8 & 0,9 & 0,7 & 0,6 & 1,0 & $-*$ & 1,1 \\
\hline $17(2)^{*}$ & 0,3 & 0,6 & 0,8 & 0,9 & 0,8 & 1,0 & $-*$ & 0,9 \\
\hline $18(1)^{*}$ & 1,3 & 1,1 & 1,1 & 0,9 & 0,9 & 1,3 & $-*_{-}$ & 0,9 \\
\hline $19(5)^{*}$ & 0,4 & 0,7 & 0,8 & 0,9 & 0,8 & 1,2 & $-*_{-}$ & 0,9 \\
\hline 20 & 0,4 & 0,5 & 1,2 & 0,7 & 0,5 & 0,6 & $-*$ & 0,9 \\
\hline $21(3)^{*}$ & 0,4 & 0,5 & 0,8 & 1,4 & 0,7 & 1,2 & $-*$ & 1,0 \\
\hline 22 & 0,4 & 0,9 & 0,8 & 1,0 & 0,9 & 1,4 & $-*_{-}$ & 1,0 \\
\hline 23 & $-*$ & 0,6 & 0,8 & 0,9 & 0,8 & $-*_{-}$ & $-*$ & 1,0 \\
\hline 24 & 0,5 & 1,1 & 0,8 & 1,0 & 1,0 & 2,0 & 1,0 & 0,9 \\
\hline 25 & 0,9 & $-*_{-}$ & 1,1 & 1,5 & 0,7 & $-*_{-}$ & $-*$ & 1,3 \\
\hline 26 & $-*_{-}$ & 0,5 & 0,4 & 1,4 & 1,4 & $-*$ & $-*$ & 0,6 \\
\hline 27-Verão-99-(1)* & 0,5 & 1,0 & 0,9 & 1,0 & 0,9 & 1,3 & $-*$ & 1,2 \\
\hline 28-Verão-99- (2)* & 0,5 & 0,7 & 0,8 & 0,8 & 0,7 & 1,2 & $-*_{-}$ & 0,9 \\
\hline 29-Verão-99-(3)* & 0,3 & 0,6 & 0,7 & 0,9 & 0,8 & 1,0 & $-*$ & 1,0 \\
\hline 30-Verão-99-(4)* & 0,3 & 0,8 & 0,7 & 0,9 & 0,7 & 1,0 & $-*$ & 1,0 \\
\hline 31-Verão-99-(5)* & 1,0 & 0,8 & 0,7 & 0,8 & 0,8 & 0,9 & $-*_{-}$ & 1,1 \\
\hline 32-Inverno-99-(1)* & 0,5 & 1,1 & 0,9 & 1,1 & 1,0 & 2,0 & 1,0 & 0,9 \\
\hline 33-Inverno-99-(2)* & 0,6 & 0,7 & 0,7 & 0,7 & 0,7 & 3,6 & $-*$ & 0,8 \\
\hline 34-Inverno-99-(3)* & 0,5 & 1,0 & 0,9 & 1,0 & 0,7 & 1,4 & $-*_{-}$ & 1,0 \\
\hline 35-Inverno-99-(4)* & 0,4 & 0,8 & 0,7 & 0,8 & 0,7 & 1,1 & $-*$ & 1,0 \\
\hline 36-Inverno-99-(5)* & 0,5 & 0,7 & 0,7 & 0,9 & 0,7 & 0,7 & $-*_{-}$ & 1,0 \\
\hline 37-Verão-00-(1)* & 0,7 & 0,7 & 0,8 & 0,8 & 0,7 & 0,6 & $-*$ & 0,9 \\
\hline 38 -Verão-00-(2)* & 0,5 & 0,7 & 0,7 & 0,7 & 0,6 & 0,2 & $-*$ & 0,9 \\
\hline 39-Verão-00-(3)* & 0,6 & 0,5 & 0,7 & 0,7 & 0,6 & 0,7 & $-*_{-}$ & 1,0 \\
\hline 40-Verão-00-(4)* & 1,0 & 0,9 & 0,8 & 0,9 & 0,6 & 0,6 & $-*_{-}$ & 1,1 \\
\hline 41-Verão-00-(5)* & 0,8 & 1,2 & 0,8 & 1,0 & 1,0 & 1,1 & 0,8 & 1,3 \\
\hline
\end{tabular}

\footnotetext{
-*- Concentração do elemento $<\mathrm{LQ}_{\mathrm{f}}$. Valores de $\mathrm{EF}$ acima 1,5 estão identificados pela formatação da fonte em negrito
} 